C E N T E R F OR

E C O N O M I C

B E H A V I O R \&

I N E Q U A L I T Y

CEBI WORKING PAPER SERIES

Working Paper 01/21

JOINT RETIREMENT OF COUPLES: EVIDENCE FROM DISCONTINUITIES IN DENMARK

Esteban Garcia-Miralles

Jonathan M. Leganza

ISSN 2596-44TX

CEBI

Department of Economics University of Copenhagen www.cebi.ku.dk 


\title{
Joint Retirement of Couples: Evidence from Discontinuities in Denmark*
}

\author{
Esteban García-Miralles ${ }^{\dagger} \quad$ Jonathan M. Leganza \\ Job Market Paper
}

January 18, 2021

Click here for the latest version

\begin{abstract}
We study how social security influences joint retirement of couples. We exploit three decades of administrative data from Denmark to explore joint retirement in two complementary settings. In the first setting, we exploit the discontinuous increase in retirement observed when individuals become eligible for public pension benefits to identify the causal effects on their spouses. We find that spouses are more likely to retire right when their partners reach pension eligibility age, with a spillover effect across spouses of $7.5 \%$. We further unpack this result by studying additional margins of adjustment such as benefit claiming and earnings, and by documenting meaningful response heterogeneity. We find age differences within couples to be a crucial determinant of joint retirement, which is primarily driven by older spouses who continue to work until their younger partners reach pension eligibility. Controlling for these age differences uncovers a gender gap where female spouses are more likely to adjust their behavior to retire jointly, and this gap remains after controlling for earnings shares within couples. In the second setting, we study to what extent couples adapt their behavior to retire jointly after a reform increases pension eligibility ages. We find spillover effects across spouses comparable to those from the first setting, in which eligibility ages were stable and known by couples well in advance. This suggests that spouses do not face adjustment costs limiting their capacity to retire together after the reform.
\end{abstract}

Keywords: Joint Retirement, Pension Eligibility Age, Couples Labor Supply

JEL Classification: J14, J26, D10, H55

${ }^{*}$ We thank our advisors, Gordon Dahl, Itzik Fadlon, Miriam Gensowski and Mette Gørtz for support and guidance. We also thank Martin Browning, Mette Ejrnæs, Alex Gelber, Thomas Høgholm Jørgensen, Claus Kreiner, Søren Leth-Petersen, Torben Heien Nielsen, Benjamin Ly Serena, Adam Sheridan, Jakob Egholt Søgaard, and participants at the CEBI and Graduate Seminars at the University of Copenhagen, at the DGPE conference, and at the $45^{\text {th }}$ Spanish Economic Association Meeting for helpful comments. GarcíaMiralles gratefully acknowledges funding from the Novo Nordisk Foundation (grant no. NNF17OC0026542) and from the the Danish National Research Foundation through its grant (DNRF-134) to the Center for Economic Behavior and Inequality (CEBI).

${ }^{\dagger}$ University of Copenhagen and CEBI. (email: egm@econ.ku.dk)

${ }^{\ddagger}$ University of California, San Diego. (email: jleganza@ucsd.edu) 


\section{Introduction}

In recent decades, aging populations have led to widespread pension reform. These reforms, and pension systems in general, are often designed at the individual level, but the presence of significant spillovers within couples will have implications for projections of labor supply, budgetary estimations, and welfare analyses. Therefore, understanding the retirement behavior of couples is crucial for the design and evaluation of public policies. In line with this reasoning, recent work on household finances is shifting attention towards interactions within couples, particularly in models of labor supply and retirement decisions (Gustman and Steinmeier, 2000, 2004; An et al., 2004; Bingley and Lanot, 2007; Van der Klaauw and Wolpin, 2008; Casanova, 2010; Michaud and Vermeulen, 2011; Honoré and de Paula, 2018; Honoré et al., 2020). These structural models illustrate two opposing forces determining joint retirement: household budget constraints (i.e. income effects) and household preferences (i.e. leisure complementarities), often finding a dominant role for leisure complementarities within the household.

However, there is limited work providing convincing causal evidence of joint retirement to guide policy and model design. Providing causal estimates of joint retirement is challenged by the existence of unobserved covariates, such as preferences for leisure or types of jobs, and confounded factors, such as age, health, income shocks or shared assets. The empirical task is further hampered by the lack of suitable data and the complex design of public pension systems that often affect spouses jointly, making the identification exercise infeasible or complicating the interpretation of the estimates. For example, the U.S. context faces some of these challenges, since pension benefits are linked between spouses, as is taxation. This might explain the lack of reduced-form evidence on joint retirement decisions from this country. $^{1}$

In addition, previous estimates of joint retirement that exploit variation in retirement ages from reforms to the pension system provide local treatment effects. These effects might differ from the joint retirement effects that occur in a more general setting, where pension eligibility ages remain stable, and couples can plan their retirement well in advance. Therefore, exploring differences between estimates based on a stable setting and estimates based on a reform setting is important for policy makers concerned with effectively designing and predicting the effect of pension reforms, as it informs on whether couples face adjustment

\footnotetext{
${ }^{1}$ Hurd (1990) and Blau (1998) provide early evidence on the associations between spouses' retirement age in the U.S.
} 
costs that limit their capacity to retire together.

In this paper, we study the causal effects of pension eligibility ages on the retirement behavior of couples. We use three decades of administrative data from Denmark and two different discontinuity designs to explore joint retirement in two complementary settings. In the first setting, we study the effect of reaching pension eligibility age when the eligibility age remains stable and is known by couples well in advance. We study the period 19912013, where the early pension eligibility age remained constant at age 60, and we exploit the discontinuous increase in retirement observed when individuals reach that age to identify the causal effects on their spouses, controlling flexibly for the effect of spousal age. We find that one year after reaching their own early pension eligibility age, individuals are 20 percentage points more likely to be retired. We then show how reaching pension eligibility ages has a spillover effect on spouses, as we document a sharp 1.5 percentage point increase in the likelihood of spouses to be retired as well. This amounts to a scaled spillover effect of $7.5 \%$.

We then leverage our detailed administrative data to study other pertinent margins of adjustment as well as to investigate heterogeneous responses. Using the same discontinuity design, we also find spillovers to spouses in pension claiming and in labor market earnings. Furthermore, through our heterogeneity analysis we find that the ability to claim seems to be a major determinant of joint retirement, as younger spouses cannot yet claim their own benefits if they retire when their older partner reaches pension eligibility. Indeed, we find that joint retirement is primarily driven by older spouses who work past their pension eligibility age, while waiting for their younger spouse to become eligible as well. We also find a strong gender difference; female spouses are more likely to adjust their retirement age to make it coincide with the pension eligibility age of their male partners. Importantly, this result is only revealed when we control for the age composition of the couple, since older partners (who we show to be the most responsive) are disproportionally males and this confounds the gender difference observed from a simple comparison of male and female spouses. This gender difference prevails when we further control for relative earnings within the couple, suggesting that gender norms may be playing a role. A closer analysis of heterogeneous responses by relative earnings suggests joint retirement patterns consistent with the opportunity cost of retirement, although these effects are limited. We observe that younger spouses who are secondary earners are more likely to retire jointly by retiring earlier, while older spouses who are primary earners are more likely to retire jointly by retiring later. We also investigate the evolution of joint retirement over time and find that it has been stable over the last two decades. 
In the second setting, we study spillover effects around the same early pension eligibility age, but in the context of a population-wide reform that increased eligibility ages discontinuously by birth cohort, starting in 2014. We leverage administrative monthly data on earnings and public benefits to estimate a local difference-in-differences model of the effect of the reform. We show that the reform generates a strong first stage, as affected individuals are induced to work longer to comply with the new pension eligibility ages. We then estimate a significant spillover on spouse retirement of $9 \%$, suggesting that the spillover identified in the first, stable setting carries over to our reform setting. Our results show that couples are able to adjust their behavior in response to the reform to retire jointly at a similar rate as couples in the previous, stable period.

Our paper is primarily related to a small number of recent studies that explore the effect of pension eligibility ages on joint retirement. Of these, two stand out. Lalive and Parrotta (2017) exploit survey data from a Swiss census and the sharp change in retirement induced by gender-specific pension eligibility ages, and find evidence of spillover effects on female spouses. Atalay et al. (2019) exploit survey data from Australia and a reform that increased the pension eligibility age of females and find evidence of spillovers to their husbands. Two other studies use administrative data, both of which exploit variation in retirement ages from reforms that affected a subgroup of public sector workers. Bloemen et al. (2019) find spillover effects to Dutch women from a reform that temporarily lowered the pension eligibility age, but their setting prevents them from studying spillovers to men. Selin (2017) exploits a reform in Sweden that delayed full pension eligibility ages for a subgroup of mostly female workers, and does not find evidence of any significant spillover effects to their husbands. Finally, Hospido and Zamarro (2014) and Banks et al. (2010) explore crosscountry differences in statutory retirement ages and find spillover effects to European women and to British men respectively. ${ }^{2,3}$

This paper makes several contributions which, altogether, provide the most comprehen-

\footnotetext{
${ }^{2}$ Other studies on joint retirement have considered reforms that indirectly affect retirement through changes in the pension design. Baker (2002) investigates a Canadian spouse allowance that is means-tested jointly with the partner's wage giving them shared financial incentives and finds evidence of joint retirement. Coile (2004) explores the financial incentives to retire of each spouse and its interrelation, using the Health and Retirement Study. Stancanelli (2017) studies a reform that increases the contribution period needed to claim full pension benefits in France, finding very small effects for joint retirement. Kruse (2020) finds significant spillovers to spouses working in the public sector after the removal of the earnings test on early pension benefits of private sector workers in Norway.

${ }^{3}$ We also relate to the large literature that studies the impact of pension eligibility ages on own retirement: E.g. Mastrobuoni (2009), Behaghel and Blau (2012), Staubli and Zweimüller (2013), Cribb et al. (2016), Manoli and Weber (2016), Geyer and Welteke (2019), Haller (2019), Nakazawa (2019), and Deshpande et al. (2020).
} 
sive evidence on how pension eligibility ages causally impact spousal retirement. First, we provide evidence from two complementary settings derived in the same context, which goes beyond previous literature that has only been able to study joint retirement in one setting or another. By comparing the two settings, we can test whether reforms to pension eligibility ages induce similar joint retirement responses as in a stable setting. This provides valuable information for the design and evaluation of public policies, and it helps to connect estimates provided by previous studies.

Second, we advance the understanding of mechanisms behind joint retirement by studying new margins of adjustment and response heterogeneity. We are able to explore heterogeneity by gender that is not confounded by age differences, and where previous literature has reported mixed results. Also, by observing couples further back in time we are able to compute their predetermined earnings shares and to explore its implications for heterogeneity.

Third, our analysis is the first one to combine a number of desirable features for the study of joint retirement. We study a pension system where males and females have the same eligibility age, as is the case in most modern pension systems (OECD, 2015), and where taxation and pension benefits are independent between spouses. In addition, we study a major reform that is being adopted in many other countries and that affects a majority of the population, as opposed to a particular subgroup. Finally, we exploit third-party reported administrative records for the entire population of Denmark and clear quasi-experimental designs.

The paper is structured as follows. Section 2 describes the institutional background. Section 3 presents the data and the samples of analysis. Section 4 lays out our empirical strategy for estimating the effect of reaching a stable pension eligibility age and reports the

results. Section 5 describes the reform and the estimating strategy, and then reports the results for the effect of increasing pension eligibility ages. Section 6 concludes.

\section{Institutional Background}

The Danish retirement system is broadly typical of other developed countries (OECD, 2019). The two primary sources of retirement income are benefit payments from public pensions and savings in private retirement accounts, with the latter coming from personal or employer contributions during working life.

Pension benefits come from two main sources. The Old Age Pension (OAP) provides universal retirement income security at old ages, and the Voluntary Early Retirement Pen- 
sion (VERP) provides early retirement benefits for those who choose to participate in the program. The majority of workers participate, about $80 \%$ of the birth cohorts we study. As VERP plays a major role in determining labor supply and retirement patterns of the Danish population, we focus our analysis on the VERP eligibility age.

Voluntary Early Retirement Pension. The VERP program, introduced in 1979, provides access to early retirement benefits, traditionally from age 60. Participating in VERP requires making modest contributions to qualified unemployment insurance funds during working life. Benefits are flat-rate and result in a fixed amount paid to all workers equal to roughly $\$ 27,000$ annually (in 2010 USD).

The decision to claim VERP benefits is tightly linked to retirement, although they are technically separate decisions. The reason for this tight link is that the design of VERP produces strong incentives to retire at the same time as claiming. First, individuals must be "available to the labor market" in order to transition to VERP, that is they must be employed or actively searching for jobs or on a special transition pension (delpension). Hence, if individuals choose to leave the labor market before reaching VERP eligibility age, they will potentially forgo 5 years of benefits. Second, there are no actuarial adjustments for deferring claiming, so delaying claiming by one year amounts to a foregone year of benefits. Third, benefits are also subject to substantial means testing against labor market earnings at essentially 100\%, which creates strong disincentives to keep working after VERP benefits are claimed, and against private retirement accounts.

The VERP program has remained fairly stable over time. Importantly, during the period 1991-2013, which we use in our first analysis, the VERP eligibility age remained constant at age 60. Two changes occurred during this period that are worth mentioning. First, the number of years that an individual has to contribute to an unemployment fund to qualify for VERP increased over time. ${ }^{4}$ Second, a pension reform in 1999 introduced incentives for individuals to delay claiming of VERP benefits by two years, to age 62. By postponing claiming to age 62 the flat-rate benefits are slightly increased (from approximately $\$ 27,000$ to $\$ 29,600)$ and they are no longer means-tested against private pension accounts. The effect of the reform was a mild decrease in the number of people claiming at age 60, and a new discontinuous increase at age 62 . Across our different analyses we show that this reform does

\footnotetext{
${ }^{4}$ From 1985, individuals had to contribute for 15 years out of the last 20 years. In 1990 the number of years increased to 20 out of the last 25, and in 1995 it increased to 25 out of the last 30.
} 
not meaningfully affect our results. ${ }^{5}$

In 2011 the Danish government announced a pension reform increasing pension eligibility ages in 6 month steps contingent on birthdate. Both the VERP and OAP ages increased, as well as the incentivized VERP age, while all other characteristics of the program remained unchanged. In Section 5 we describe this reform in detail, and we exploit the first discontinuity created by the reform to study the effect on joint retirement. We focus on the first cohort affected, those born after the cutoff date of January 1, 1954, whose VERP eligibility age was raised from 60 to $60 \frac{1}{2}$, and who are first impacted in 2014 when they turn 60 .

Two features of the VERP program make it ideal to study joint retirement behavior. First, the pension benefits are independent between spouses. The decision to claim or retire does not have any direct effect on the pension benefits of the spouse. Therefore, we can rule out direct effects on the pension benefits of spouses as a mechanism for joint retirement in our analyses. ${ }^{6}$ Second, the pension eligibility age is the same for men and women over the entire period considered, which has two advantages. First, our setting is representative of modern systems in most OECD countries that have eliminated the gender gap in statutory pension eligibility ages over the last decades (OECD, 2015, 2017). Second, we can study heterogeneous effects by gender, age composition and income shares within the couple that are not affected by differential pension eligibility ages. ${ }^{7}$

Old Age Pension. The OAP provides universal old-age benefits. The eligibility age was traditionally 67, and it was lowered to 65 by the 1999 reform. Therefore, less than 5\% of the spouses in our samples of analysis are old enough to be eligible for OAP. Benefits are roughly $\$ 15,000$ for married or cohabiting individuals and $\$ 20,000$ for single individuals. Individuals are eligible for full OAP benefits if they have resided in Denmark for at least 40 years, and benefits are reduced proportionally if individuals have resided for a shorter period. Claiming benefits is an active choice, and the decision to claim is separate from the decision to cease working. From 2004, individuals can defer claiming OAP benefits and receive (approximately) actuarially-fair increases in benefits. Also, the means testing of OAP

\footnotetext{
${ }^{5}$ While not a reform of VERP, between 1992 and 1996 a transitional benefits program allowed long-term unemployed above age 55 (and above age 50 from 1994) to retire with similar conditions as the VERP program.

${ }^{6}$ This is in contrast to Baker (2002) who studies exactly these direct links between spouses' pension benefits, and also to the second empirical design of Atalay et al. (2019) which is based on the characteristics of Vietnam veterans' pension system.

${ }^{7}$ Note that this is in contrast to the two closest related papers to ours. Atalay et al. (2019) exploit a reform that raises women's pension eligibility ages to converge to that of men's. Lalive and Parrotta (2017) study a stable period where retirement ages were different beween men and women.
} 
is less strict than that of VERP.

\section{Data and Sample of Analysis}

\subsection{Data}

We use administrative data covering the entire population of Denmark over the period 19862014. Using personal identifiers for each individual, we combine different registers with information on labor market outcomes, pension benefits, socio-demographics and family linkages. Variables are third-party reported on an annual basis and contain a large degree of disaggregation. Individuals cannot select themselves out of the registers, and they only exit the registers if they migrate out of the country or die.

In addition, we also use monthly-frequency register data on earnings for all employees in Denmark and on pension benefits for the entire population, both of them available from 2008. We combine this data with the annual-frequency registers using the same individual identifiers. This allows us to define retirement ages with more precision, which is crucial for the analysis of the 2014 reform that increased the pension eligibility age by 6 months. ${ }^{8}$

\subsection{Key Variables.}

One advantage of our data is that we can measure different margins of labor supply and retirement behavior. We consider three main outcomes, which are defined either at the end of each calendar year (when using the annual data in the first, age-based setting) or as halfyear measures (when using the monthly data in the second, reform-based setting, since the reform increased the VERP eligibility age by 6 months).

Retirement: We define retirement as ceasing to earn labor market income. For the agebased design we use the annual data to define retirement as the year in which individuals earned income for the last time. ${ }^{9}$ Therefore, we define retirement as an absorbing state where the retirement variable takes the value one thereafter. In the robustness section we show that the results are robust to using a flow definition of retirement where we allow individuals to retire multiple times. These definitions are standard in the retirement literature (Coile and Gruber, 2007; Deshpande et al., 2020). For the reform-based design, we use the monthly

\footnotetext{
${ }^{8}$ This new dataset, often referred to as eIncome, is described in more detail in Kreiner et al. (2016).

${ }^{9}$ We allow for some small positive income, equivalent to 1 month of average earnings, to accommodate the fact that individuals can receive some labor income after they have retired, such as holidays payments or delayed wages.
} 
data to define a dummy that takes the value one if an individual works past the first half of the year (that is, past July 1) in a given year. This accommodates the fact that individuals unaffected by the reform become eligible for benefits at the beginning of the reform year (2014) when they turn 60, whereas individuals affected by the reform become eligible at least 6 months later, when they reach age $60 \frac{1}{2}$.

Claiming: We define claiming as receiving pension income, either VERP or OAP. For the age-based design we define an indicator equal to one if an individual receives any pension income in a given year. For the reform-based design we define an indicator that takes the value one if an individual received pension income before July 1 in a given year.

Earnings: In both research designs we use taxable annual labor market earnings from the annual registers. We winsorize this variable at the $1^{\text {st }}$ and $99^{\text {th }}$ percentile to reduce the influence of outliers. We adjust this variable for inflation using 2010 as a baseline and convert Danish kroner to U.S. Dollars using the exchange rate 1 USD $=5.56$ DKK.

\subsection{Samples of Analysis}

We define two samples of analysis, one for each research design. For both of our research designs we start with the full population of Danish couples who reside in Denmark between 1991 and 2014. We define couples as those who are either married, or in a registered partnership, or cohabiting. To avoid endogenous changes in marital status around the time of pension eligibility we identify couples when they are both below age 60 and observe them for as long as they remain together. We restrict the analysis to couples who are up to 8 years apart from each other, which excludes around $5 \%$ of the sample on each side of the distribution. We illustrate this in panel (a) of Appendix Figure A.4.

We focus the analysis on dual-earner couples. First, we restrict the sample to couples where the reference individual (that is, the focal partner who reaches their own pension eligibility age) has earned labor income at least once between ages 55 and 59. All cohorts in our sample of analysis are observed back to age 55 since we have data from 1986 . We also exclude reference individuals who are self-employed or on disability benefits at least once between ages 50 and 59, as they are subject to different rules and regulations of the VERP scheme. Second, we restrict the sample to couples where the spouse has earned labor income at least once between ages 50 and 59. We use this longer period for spouses to ensure that our sample does not exclude younger spouses who retire in their early 50s, as they can 
potentially retire jointly with their older partners. ${ }^{10}$

Age-based sample. For our age-based design, we consider the period 1991-2013, where the early pension eligibility age remained stable at age 60 . This provides us with more than two decades of observations from individuals who faced the same pension eligibility age. We focus the analysis on couples where the reference individual is 57 to 60 years old, which leads to a sample size of 367,585 couples and 2,206,044 couple-year observations.

Reform-based sample. For our reform-based design, we consider the period 2008-2014, starting in 2008 because the monthly-frequency data is only recorded from that year. To focus on individuals who are more likely to be impacted by the reform, we restrict this sample to reference individuals who have made qualifying contributions to the VERP program at least once between ages 50 and 59. Note that we cannot impose this restriction on the full age-based sample because we do not observe contributions far back in time, but in the robustness section we show that our results from both designs are robust to this decision. ${ }^{11}$ In our baseline specification, we focus on individuals born within a 3-month window on either side of the January 1, 1954 cutoff, and we balance the sample, leading to a sample size of 10,321 couples and 73,395 couple-year observations.

Table 1 presents summary statistics for the two samples and for the corresponding unrestricted population. The first four columns correspond to the age-based period of analysis (1991-2013) and the last four columns correspond to the reform-based period of analysis (2008-2014). First, we can compare the analysis samples to their corresponding population samples. We note that both reference individuals and spouses in the analysis samples have higher earnings, higher education, and are less likely to be retired before age 60 . This is mainly a consequence of restricting the analysis to dual-earner couples and to those who did not receive disability benefits in the past. Also note that the age difference between spouses is similar between the analysis sample and the population, but the standard deviation is smaller due to the restriction that drops spouses who are more than 8 years apart. Second, we can compare the two analysis samples. Overall the two samples are similar, but the reform-based sample has a smaller share of males ( $47 \%$ against $52 \%$ ), higher earnings

\footnotetext{
${ }^{10}$ Note that there are four cohorts of spouses that we cannot observe before age 60 to impose the restriction, and therefore we keep all those spouses, who represent $0.4 \%$ of the sample. Similarly, there are nine cohorts of spouses that we cannot observe during the entire period between ages 50 to 59 . In this case, we impose the restriction based on the years that we observe. This affects $12 \%$ of the spouses, of which $80 \%$ are observed for 5 or more years.

${ }^{11}$ Specifically, we show that our age-based results are robust to imposing the restriction for the subsample of observations over 2008 to 2013, for whom we can observe past contributions. We also show that the reform-based results are robust to not imposing the restriction.
} 
(\$64,156 against $\$ 60,289)$ and is slightly more likely to be retired before age 60 (16\% against $14 \%$ ), but these differences are not statistically significant. These differences are in line with the effect of restricting the reform-based sample to VERP contributors, as females are more likely to contribute to the program. The age difference between partners in both analysis samples is similar and so are the standard deviations.

\section{The Effect of Reaching Pension Eligibility Age}

\subsection{Age-Based Discontinuity Design}

To identify the causal effects of individuals reaching pension eligibility age on their own retirement and on their spouses, we exploit the discontinuity that occurs around the early pension eligibility age. Specifically, we study the retirement patterns of reference individuals and their spouses around the eligibility age of the reference individuals, that is around age 60. Importantly, when analyzing spouses' retirement patterns we control flexibly for the effect of own age on their own retirement behavior.

We lead our analysis with a graphical illustration of the retirement patterns of the reference individuals and their spouses, which then guides our estimation strategy and allows us to evaluate the assumptions of the estimation model.

Note that each member of a couple can potentially appear both as the reference individual and as the spouse in the analysis, as long as they are observed at ages 57-60 during the period considered. This reflects the dual nature of the couples' decision, and our design allows us to study their retirement behavior from both sides, observing them as reference individuals when they reach their pension eligibility age and as spouses, with respect to their partners' eligibility age. In the heterogeneity analysis we will, nevertheless, split the sample by age composition and gender and each member of the couple will appear only as either the reference individual or the spouse.

\subsection{The Effect of Reaching Pension Eligibility on Own Retirement}

We begin by analyzing the retirement behavior of reference individuals around their own pension eligibility age. Specifically, in Figure 1 we pool individuals for the period 1991-2013 and plot raw means of each outcome variable for the reference individual against their own age. As expected, given the strong incentives to retire exactly at the pension eligibility age, we observe a clear discontinuous jump in all outcomes at age 60. An important feature of the data is that the outcome variables are measured at the end of each calendar year, and so 
is age, which we round up to months. Hence, individuals who turn 60 early in the year can claim their pension earlier that year than those who turn 60 later in the year. This induces a gradual phasing-in of the exposure to early retirement eligibility as monthly age increases from 60 to 61, a pattern captured by Figure 1.

We are interested in the "full-exposure" effect of being eligible for one entire calendar year. Individuals who are fully exposed are those who turn 60 at the beginning of January, becoming eligible for early retirement at that moment. These individuals are exposed to early pension eligibility for 12 months by the time their information is recorded in the administrative data in December. In contrast, individuals who turn 60 later in the year are eligible for a shorter period of time that year, so they are only partially exposed. Our estimation strategy exploits information from both partially and fully exposed individuals to estimate the full-exposure effect with greater precision.

We quantify the full-exposure effect by estimating the following piecewise linear regression, which is closely guided by the graphical analysis:

$$
y_{i t}=\alpha+\beta_{1} a g e_{i t}+\beta_{2} \mathbb{1}\left\{a g e_{i t} \geq 60\right\}+\beta_{3} \mathbb{1}\left\{a g e_{i t} \geq 60\right\} \cdot a g e_{i t}+\sum_{c=1991}^{2013} \kappa_{c} \cdot D_{c}+\epsilon_{i t}
$$

where $y_{i t}$ is the outcome of interest for reference individual $i$ at time $t, a g e_{i t}$ is monthly age of the reference individual at the end of the calendar year, and $\mathbb{1}\left\{a g e_{i t} \geq 60\right\}$ is an indicator variable that takes the value one if the monthly age of the reference individual is 60 or above and zero otherwise. The model therefore estimates a discontinuous jump at monthly age 60 and a differential trend thereafter, as suggested by the graphical analysis. $D_{c}$ are calendar year dummies. We estimate this regression for individuals between monthly ages 57 and just below $61 .^{12}$

The full-exposure effect is then given by $\beta_{2}+\frac{11}{12} \cdot \beta_{3}$. This estimator captures the treatment effect of being eligible for early pension during one full calendar year. It is composed of a sharp change in levels at the eligibility-age cutoff, captured by $\beta_{2}$, and a change in trends, captured by the slope parameter $\beta_{3}$ that captures the effect of one year of eligibility from age 60. We plot the parametric fit of this model in Figure 1. The full-exposure effect corresponds

\footnotetext{
${ }^{12}$ Because the outcome variables are measured in December, individuals who turn 60 in December often do not have time to receive pension income until the next year. This is clearly seen in Figure 1, panel (b), where the dot for December is much lower. To prevent this from biasing our estimates we exclude these individuals by adding a dummy variable that takes the value one if their monthly age is exactly 60 . In Table 5 of the robustness section we show that the results are largely unaffected if these individuals are kept.
} 
to the vertical distance between the solid line and the dashed line just below age $61 .^{13}$

The first row of Table 2 reports the full-exposure estimates for the different outcomes of the reference individual. The first column reports the full-exposure effect on retirement. The estimate is 0.2034 , which means that reaching pension eligibility age increases the share of retired individuals by around 20 percentage points. Note that the share of retired individuals before they reach pension eligibility is also positive, around $16 \%$ before age 60 , as illustrated in panel (a) of Figure 1. This shows that individuals can also retire before they reach pension eligibility. ${ }^{14}$ The second outcome of interest, pension claiming, is reported in the second column. The point estimate is 0.35 , so around $35 \%$ of individuals claim VERP benefits by the end of their first year of eligibility. The effect for claiming is larger than for retirement for two reasons. First, it is not possible to claim VERP benefits before age 60, as illustrated in panel (b) of Figure 1, and second, individuals who claim can still have positive earnings in the same year. Finally, the third column reports the full-exposure effect on annual labor market earnings, which can potentially reflect responses both on the extensive margin and on the intensive margin. We estimate a decrease of $\$ 8,642$ in annual earnings after one year of exposure to pension eligibility.

Overall our results show that reaching pension eligibility leads to a strong first stage. Individuals are discontinuously more likely to retire after age 60 . We now turn to estimate the causal effects of pension eligibility on spousal retirement behavior.

\subsection{The Effect of Reaching Pension Eligibility on Spouses}

For the spillover effect on spouses, we follow a similar empirical strategy as for reference individuals. The main difference is that we need to control for the effect of spouse's own age on their retirement behavior so that we can isolate the causal effect of their partner's pension eligibility.

We lead the analysis with a nonparametric illustration of spouse retirement patterns around their partners' age, cleaned from the effect of the spouses' own age. Specifically, we

\footnotetext{
${ }^{13}$ A similar methodology is used by Fadlon et al. (2019) to study the effect of Social Security's survivors benefits on labor supply in the U.S. Also, Nielsen (2019) studies the effect of retirement on health exploiting the same age-discontinuity in Denmark.

${ }^{14}$ We have argued in Section 2 that there exists strong incentives to claim right at the early pension eligibility age, but individuals might cease to earn labor income earlier than 60 for a number of reasons: they might become unemployed or claim a partial pension until they turn 60, they might voluntarily stop working even if that implies the inability to claim VERP later on, and lastly, not all individuals in our sample qualify for VERP, as explained in Section 3, around $80 \%$ of the individuals in the age-based sample of analysis made contributions to qualify for VERP.
} 
plot the residuals from the following regression:

$$
y_{i t}^{s}=\alpha+\sum_{a=49}^{69} \delta_{a} \cdot D_{a}^{s}+\sum_{a=49}^{69} \gamma_{a} \cdot D_{a}^{s} \cdot D_{g}+\sum_{c=1991}^{2013} \kappa_{c} \cdot D_{c}+\varepsilon_{i t}
$$

where $y_{i t}^{s}$ is the outcome variable of interest for spouse $s$ of individual $i$ at time $t, D_{a}^{s}$ are dummy variables for spouses' monthly age, and $D_{g}$ is a gender dummy. The residuals $\hat{\varepsilon}_{s t}$ therefore capture the spouses' retirement behavior that is not explained by their own age and gender. ${ }^{15}$

The dots in Figure 2 plot spousal residuals $\hat{\varepsilon}_{i t}$ binned over the monthly age of reference individuals. This illustrates the spouses' retirement patterns that are driven by their partner's age. We observe that spousal residuals change discontinuously right when their partner becomes eligible for early pension at age 60, resembling the same pattern we observed for the reference individuals themselves.

Guided by this graphical analysis, we estimate a parametric model that quantifies the causal effect of one partner reaching pension eligibility age on the retirement behavior of their spouse. The estimating equation is similar to equation (1) for the reference individual, but with spouses' outcomes as the dependent variables and additional controls for spouses' age and gender that do not impose any functional form. The estimating equation is:

$$
\begin{gathered}
y_{i t}^{s}=\alpha+\beta_{1} \text { age }_{i t}+\beta_{2} \mathbb{1}\left\{\text { age }_{i t} \geq 60\right\}+\beta_{3} \mathbb{1}\left\{\text { age }_{i t} \geq 60\right\} \cdot \text { age }_{i t}+ \\
\sum_{a=49}^{69} \delta_{a} \cdot D_{a}^{s}+\sum_{a=49}^{69} \gamma_{a} \cdot D_{a}^{s} \cdot D_{g}+\sum_{c=1991}^{2013} \kappa_{c} \cdot D_{c}+\epsilon_{i t}
\end{gathered}
$$

where $y_{i t}^{s}$ is the outcome of interest for spouse $s$ of individual $i, a g e_{i t}$ is age of the reference individual in months, and $\mathbb{1}\{a g e \geq 60\}$ is an indicator variable that takes the value one if the reference individual is 60 or older (in terms of monthly age) and zero otherwise. $D_{a}^{s}$ are dummy variables for spouses' monthly age, and $D_{g}$ is a gender dummy. We estimate this regression for the same sample of reference individuals, between ages 57 to 61, as before.

The full-exposure effect is again given by $\beta_{2}+\frac{11}{12} \cdot \beta_{3}$. For illustrative purposes, Figure 2 superimposes the parametric fit of the model estimated in equation (3) over the residuals from equation (2). The full-exposure effect corresponds to the vertical distance between the solid and dashed lines just below age 61 . The second row of Table 2 reports the full-exposure

\footnotetext{
${ }^{15}$ An alternative approach to this methodology would be to estimate equation (2) adding age dummies for the reference individual and plot those coefficients. We show that the result is similar in Appendix Figure A.1.
} 
effect on spouses from their partner reaching pension eligibility age. The effects on all three spousal outcomes are statistically significant at the $1 \%$ level. These point estimates can be viewed as the reduced-form effects on spouses.

To judge the size of joint retirement behaviors, we report "scaled effects" in the last row of Table 2, defined as the full-exposure effect on the spouse divided by the full-exposure effect on the reference individual. These scaled effects are our preferred measure for reporting and interpreting joint retirement spillovers, as they are comparable across different outcomes, samples of analysis, and empirical strategies, including our reform-based design. We compute standard errors for these scaled estimates by bootstrapping (Andrews and Buchinsky, 2000; MacKinnon, 2006). ${ }^{16}$

The scaled effect on the retirement outcome is $7.5 \%$. That is, for every 100 individuals who retire right when they reach their early pension eligibility age, about 8 of their spouses are induced to retire as well. This is after controlling for the effect of the spouses' age on their own retirement behavior.

Claiming leads to scaled effect of $3.4 \%$. This effect is smaller than the one for retirement for two reasons. First, the denominator is larger, that is, the full-exposure effect on the reference individual is larger for claiming than for retirement as discussed earlier. Second, the numerator is slightly smaller, the full-exposure effect on the spouses is smaller because of spouses who retire but do not claim. Knowing the joint retirement effect on claiming is important for policy and fiscal estimations, but for the reasons mentioned above it does not fully capture joint retirement behavior. ${ }^{17}$ In the next subsection we explore the interaction between claiming and the age composition of couples and its implications for heterogeneous joint retirement responses.

For earnings, the scaled effect is $9.8 \%$. Note that this outcome potentially captures both extensive margin responses and intensive margin adjustments that can be in the form of hours worked, choice of job, or effort. However, we cannot conclude that there are significant intensive margin responses based on the larger size of the scaled effect for earnings compared to retirement. Note that the size of the scaled effect for earnings depends on the relative

\footnotetext{
${ }^{16}$ Note that these scaled effects are conceptually similar to the estimates from an instrumental variables approach. We use scaled effects because they allow for a more flexible estimation of the second stage (the spouses' full-exposure effect) by estimating the jump at 60 and the differential trend separately. An instrumental variables approach, instead, imposes the same functional form as the first stage (the instrumented outcome of the reference individuals).

${ }^{17}$ For an analysis of retirement and claiming in the U.S. see Deshpande et al. (2020). Note that while deferring claiming in the U.S. leads to actuarial adjustments of future pension benefits, in the VERP program there is no such actuarially fair updating, and therefore the decision to claim and retire are more closely related.
} 
earnings within couples, and the scaled effect will increase if the spouses who adapt their behavior to retire jointly are mainly the primary earners, even if adjustments occur only through the extensive margin. This in turn depends on the response heterogeneity, which we analyze in the following section.

\subsection{Explaining Joint Retirement: Heterogeneity and Mechanisms}

The aggregate results from the previous section, reported in Table 2, mask important differences across different types of couples. In this section, we explore differences across three characteristics: age differences within the couple, gender, and primary earner status. We are in an exceptional position to do so, due to our large sample size and the symmetric design of the Danish pension system, where men and women face the same pension rules and pension benefits are independent between spouses.

\subsubsection{Age differences within the couple}

We study the effect that relative age within partners has on joint retirement and find that it plays a crucial role. We begin our analysis by splitting our sample based on whether spouses are older or younger than their partners who are reaching age 60. For each of these subsamples we replicate the analysis and report the results in columns (1) and (2) of Table 3. Focusing on the retirement outcome, we observe that the scaled effect is $10 \%$ for older spouses and only $2.9 \%$ for younger spouses, while still highly significant. These results suggest an important role for the ability to claim own pension benefits in the decision to retire jointly. Older spouses who retire right when their younger partners reach pension eligibility age must continue working past their own pension eligibility, and can then claim benefits themselves. In contrast, younger spouses who retire right when their older partners reach pension eligibility age cannot claim their own benefits, since they themselves have not yet become eligible. This is a potentially financially costly decision, especially if it entails giving up the right to claim VERP later on due to the "transition to VERP" rules explained in Section 2. Overall, our results show that in this context couples favor the joint retirement path where the older spouse works past their eligibility age rather than the younger spouse retiring before reaching pension eligibility age.

Next, we explore the effect of age differences in more detail. Specifically, we define subsamples based on smaller intervals of their age differences and estimate joint retirement spillover for these subsamples. The results are reported in Figure 3, where we plot the scaled effects as spouses' age increases relative to their partners. We observe that the largest 
scaled effects are concentrated among spouses who are older, but not too far apart from their partners' age. Specifically, focusing on the retirement outcome, reported in panel (a), we find the largest effect (above 10\%) for spouses up to 2 years older, followed by spouses who are between 2 and 4 years older. The effect decreases for spouses who are more than 4 years older than their partners. For younger spouses, we do not find evidence of differential spillovers in joint retirement as the difference between partners' age increases. The point estimates remain small and stable around the same size as for the pooled subsample of younger spouses $(2.9 \%)$, although less precisely estimated due to the smaller sample size.

Overall, these results point to age differences between partners and the ability to claim as crucial determinants of joint retirement. Policies that aim to account for the joint retirement of couples must account for the economic incentives faced by each age group, and particularly for the ability of each partner to claim. In our setting, younger spouses cannot claim benefits of their own if they retire when their partner reaches early pension eligibility. However, in other settings, such as those centered on later pension eligibility thresholds where younger spouses can also claim their own benefits when they retire at the same time as their older partners, the joint retirement spillover of younger spouses might be larger. In addition, economic analysis of intra-household behavior should account for the effect of the age-composition of couples.

\subsubsection{The effect of gender}

Next, we explore heterogeneity by gender, a dimension where previous studies have found particularly mixed results. Some of the difficulties faced by the literature include pension systems where eligibility ages differ by gender or where a reform affected one gender only, lack of statistical power that hampered the estimation of small effects, and failure to account for confounded effects between age differences and gender. Our analysis overcomes these challenges, as there are no gender differences in the Danish pension system, benefits and taxation are independent between spouses, and we have statistical power to estimate gender differences controlling for other confounding factors such as age differences.

We begin by replicating our analysis over a simple split by gender. Column (3) of Table 3 presents results for the subsample of male spouses and column (4) for female spouses. The scaled effects for both male and female spouses is $7.5 \%$, which could erroneously lead us to conclude that both genders are equally likely to adapt their behavior to retire jointly with their partner.

However, this simple split by gender masks important differences in the relative age 
between spouses. As in most countries, Danish men tend to be the older member of the couple. ${ }^{18}$ In our analysis sample, males are around 2 years older than females, as we illustrate in panel (b) of Appendix Figure A.4. We have shown that older spouses are much more likely to retire jointly, therefore the estimate found for men confounds the fact that the subsample of male spouses is composed by a larger share of older spouses. Therefore, to explore gender differences in joint retirement, we must control for the confounded age differences. We do so by reweighting the subsample of female spouses to match the distribution of age differences from the subsample of male spouses, and then re-estimate the spillover effect. The result is shown in column (5). We observe that the scaled effect for females rises from $7.5 \%$ to $13 \%$. We can then compare this scaled effect to the scaled effect for male spouses, reassured that the difference is not driven by the age-difference composition of both subsamples. Interestingly, we find that females clearly respond more, contrary to the conclusion that we could have reached from the simple split by gender. ${ }^{19}$

A potential explanation for these gender differences in behavior is that relative earnings within couples confound joint retirement and gender. We study the role of relative earnings in detail in the next section, but regarding its impact on the gender gap, we show that the gap we find is robust to further reweighting the sample of female spouses to have the same distribution of earnings shares as male spouses. The results are reported in column (6) of Table 3, where the scaled effect estimate for retirement remains high at $13.6 \%{ }^{20}$ Our results therefore unveil a gender gap that cannot be explained by age or relative earnings within couples, suggesting a role for gender norms. This result adds to recent findings of gender differences that cannot be explained by traditional economic incentives (Daly and Groes, 2017; Kleven et al., 2019; Gørtz et al., 2020; Lassen, 2020).

Our results also document a new source of gender differences in earnings and labor supply which, unlike previous studies that focus on childbearing and childcare, originates in the dynamics of family formation and the joint retirement behavior of couples, manifesting itself at the end of working life. Because males tend to be older than their female partners,

\footnotetext{
${ }^{18}$ Hospido and Zamarro (2014) and Coile (2004) consistently find similar age differences, of around 2 years, for different European countries and for the U.S. respectively.

${ }^{19}$ In Appendix Table A.1 we show, as an alternative to the reweighting strategy, a 4-way sample split by age difference and gender. The results are consistent with those from reweighting; older female spouses respond more than older male spouses, and younger female spouses respond more than younger male spouses.

${ }^{20}$ The gender gap remains when we further reweight the subsample of female spouses to ensure that the share who made contributions to qualify for VERP in the past is the same as in the subsample of male spouses. Note that we only observe VERP contributions for the most recent period of time and hence we perform this test for the period 2008-2013 only. The scaled spillover for retirement is $7 \%$ for males and $11.4 \%$ for females after reweighing.
} 
couples who retire together most often achieve this either by males retiring later or by females retiring earlier, therefore increasing males lifetime earnings relative to females. Note that the "grandchild penalty" found by Gørtz et al. (2020) could explain part of the gap we identify, as grandmothers retire earlier to take care of their grand children, but it does not explain it all, as we also find that older female spouses are more likely to retire later, waiting to retire together with their younger partners.

\subsubsection{The effect of relative earnings within couples}

We now focus on the role of relative earnings within couples for joint retirement. First, we compute predetermined earnings shares based on the average labor market earnings of each partner between ages 55 and 57, and report the distribution of these shares in panel (d) of Appendix Figure A.4. Then we define an indicator for who is the primary earner in the couple based on these shares, excluding couples with very similar earnings shares (those between $47.5 \%$ and $52.5 \%$, which represent $14 \%$ of the sample), although the results are robust to keeping them. Second, we replicate our analysis to estimate spillover effects over four different subsamples, distinguishing by whether the spouse is the primary or secondary earner and whether the spouse is the younger or older member of the couple. To avoid composition effects confounding our results, we reweight the primary-earner subsamples so that they match the distribution of the secondary-earner subsamples in regards to age differences and gender composition.

The results are reported in Table 4. For completeness we report the three main outcomes of interest, but note the difficulty in interpreting earnings in this context, as by construction the effect on primary-earner spouses will be larger than that on secondary-earner spouses. We focus our discussion on the scaled effects for the retirement outcome. Overall, the primaryearner status does not seem to be a major determinant of joint retirement, as the differences between primary and secondary earner spouses is small and not statistically significant. However, interpreting the estimates at face value, we observe patterns consistent with the opportunity cost of retirement. We see that among older spouses, shown in columns (1) and (2), primary earners are 1.1 percentage points more likely to retire jointly. That is, they are more likely to work past their retirement age waiting for their younger spouses to reach their own pension eligibility age. On the contrary, among younger spouses, shown in columns (3) and (4), secondary earners are 2.7 percentage points more likely to retire jointly, that is they are more likely to stop working before they reach their own pension eligibility age to retire when their older partner becomes eligible. These results are consistent with the opportunity 
cost of retirement seen as foregone earnings. The returns to continued employment are higher for primary earners, who therefore are more likely to work longer, while the foregone earnings from secondary earners are smaller, making it less costly to stop working earlier.

\subsection{The Evolution of Joint Retirement Over Time}

In our analyses we have pooled two decades of observations to obtain precise estimates of the causal effects of reaching pension eligibility age on joint retirement of spouses. In this section we provide evidence on the evolution of these estimates over time. To do so, we replicate the previous analysis over 5-year running windows. We report the evolution of the scaled effects for the three outcomes of interest in Figure 4, where each dot at year $t$ corresponds to the scaled effect estimated for the period $t-4$ to $t$. For instance, the last dot from 2013 reports the scaled effects estimated for the period 2009-2013.

Overall, we observe that joint retirement has been stable over time. The stability of the scaled effect means that despite possible changes in the take up of early retirement over time, the spillover effect on their spouses has remained stable. That is, changes in the full-exposure effect for reference individuals are followed by proportional changes in the full-exposure effect on their spouses, keeping the scaled effect ratio constant. In Appendix Figure A.5 we illustrate this by plotting the evolution of the full-exposure estimates over time for both reference individuals and spouses, for the retirement outcome.

The stability of joint retirement over time allows us to interpret the scaled effect estimates for the full period as reflecting a stable spillover behavior, as opposed to the average of an estimate that has been changing over time. As such, the size of the full-period estimates is also representative of the effect in most recent years, which are of more interest for policy and also the relevant period for comparison with the reform-based estimates derived from the 2011 reform that we present in Section 5.

\subsection{Threats to Identification and Robustness}

Our identification strategy relies on the assumption that, once we control flexibly for the spouses' age on their own retirement, the discontinuous behavior that occurs when their partner reaches pension eligibility age is caused by that event, and nothing else. In this section we provide a number of tests to assess the validity of our design.

Placebo test. To be reassured that we successfully control for the effect of the spouses' age, we carry out a placebo test. We repeat the analysis for the same sample of reference 
individuals, but we randomly assign them a fake spouse of similar age. Specifically, we assign a spouse of the same age to half of the reference individuals, and we assign spouses who are between 1 and 3 years younger or older to the other half of the reference individuals. ${ }^{21}$ In this sample, spouses are likely to retire at the same time because their ages are highly correlated and most of them reach pension eligibility age right around the same time. However, we should not observe any joint retirement behavior beyond the one due to this age correlation between spouses, given that fake spouses cannot influence each other. If our empirical strategy successfully controls for the effect of age correlations, then we should not find any evidence of joint retirement in this placebo sample. Reassuringly we do not find any, as reported in Appendix Table A.2 and Appendix Figure A.2.

Alternative specifications. In Table 5 we show that the results are robust to a series of changes in the model specification and in the sample definition. Row A reports the baseline estimates for comparison. In row B we extend the sample of analysis to include reference individuals of ages 55 and 56. In row $\mathrm{C}$ we exclude reference individuals aged 59 by adding a dummy variable to the model that takes one if the reference individual is 59 or older. This excludes monthly ages between 59 and 60 from the estimation of the counterfactual behavior. Row D drops the dummy that identifies reference individuals who turn 60 in December, so that they are included in the estimation of the jump at 60 and the differential trend afterwards. Row E allows for a nonlinear counterfactual before age 60 by adding a second order polynomial of the reference individuals' age to the model. This nonlinear specification reduces our point estimates (e.g. the scaled effect on retirement becomes $4.1 \%$ ), but note that we are fitting a second order polynomial over a short period of three years (ages 57 to 60). To account for this, in row $\mathrm{F}$ we increase the age range to include reference individuals of ages 55 and 56 (as in B) and fit a second order polynomial (as in E), obtaining spillover effects much closer to our baseline estimates. Row $\mathrm{G}$ controls for predetermined region and education of the reference individual and their spouse. Row $\mathrm{H}$ adds a dummy for individuals born after 1939, who are therefore affected by the 1999 reform that introduced incentives to claim VERP at age 62 and lowered the OAP to age 65. Row I estimates the effect over the period 2008-2013, which is almost the same period considered in the reform-based design that we present in Section 5. In row $\mathrm{J}$ we present estimates over the same period as in I, and restrict the sample to reference individuals who have made contributions to qualify for VERP at least once between ages 50 and 59. Note that we can only impose this restriction

\footnotetext{
${ }^{21}$ Note that we do not use only spouses of the same age to avoid collinearity between the age of both partners.
} 
for these later calendar years as we do not observe contributions far back in the past. Finally, in row $\mathrm{K}$ we report the scaled effect for retirement defined as a flow variable, which allows individuals to retire multiple times (see Appendix Figure A.3 for the full-exposure effects). Reassuringly, our results are robust to all these changes.

Attrition. Individuals cannot self-select out of the registers. The only two reasons for an individual to exit the registers are either migrating out of Denmark or dying. If reaching pension eligibility caused any of these two things to happen, we would miss that individual from the sample, but in no case would they be wrongly considered as retired. Note also that Nielsen (2019) finds no evidence of increased mortality at retirement studying the same age discontinuity in Denmark.

\section{$5 \quad$ Impact of Increasing Retirement Ages}

We have shown that spouses are more likely to retire right when their partners reach pension eligibility age. What happens to the joint retirement of couples when the pension eligibility age of one partner changes? In this section we study a major reform that discontinuously increased the early pension eligibility age of selected cohorts. This analysis complements the previous analyses by testing whether the joint retirement spillover that occurs in a stable setting carries over to a reform setting, or whether couples face adjustment costs that limit their capacity to retire together.

\subsection{The 2011 Pension Reform}

In May of 2011 the Danish government announced a pension reform that discontinuously increased retirement ages in six-month increments contingent on birthdate. The first increase introduced by the reform provides us with the clearest natural experiment: the early pension eligibility age (that is, the VERP eligibility age) was increased from 60 to $60 \frac{1}{2}$ for those born from January 1, 1954, while it remained at 60 for those born right before. The reform also introduced six-month increments in the incentivized early retirement age that was traditionally at age 62 and in the OAP age that was traditionally at age 65, but we maintain our original focus on the prominent early pension eligibility age. ${ }^{22}$ Other characteristics of the VERP program remained the same, including the pension benefits and its

\footnotetext{
${ }^{22}$ Cohorts born later than July 1, 1954 experienced additional increases in their pension eligibility ages that we illustrate in Appendix Figure B.1.
} 
independence between spouses. The duration of VERP remained 5 years in length because the OAP age increased as well.

The design of the VERP program, which we introduced in Section 2, creates strong incentives to retire right at the VERP eligibility age. Hence, the reform induced strong shifts in claiming and retirement ages of the affected individuals that we can use as a first stage to study spillover effects to their spouses. For more details on this reform, see GarcíaMiralles and Leganza (2020) where we identify private savings responses to this reform from individuals who were directly affected.

\subsection{Reform-Based Discontinuity Design}

To identify the casual effect of increasing individuals' pension eligibility age, we use a local difference-in-differences framework. The treatment group is composed of individuals born on January 1, 1954 or soon after, whose pension eligibility ages increase by 6 months due to the reform. The control group is composed of individuals born right before January 1, 1954, whose pension eligibility ages remain the same. In our main analysis we consider a bandwidth of three months around January 1, 1954 but we show that our results are robust to different bandwidth choices.

We asses the parallel-trends assumption and the dynamics around the announcement and implementation of the reform by estimating a dynamic difference-in-differences model over the period 2008-2014 of the form:

$$
y_{i t}^{(s)}=\alpha+\delta \cdot \text { treat }_{i}+\sum_{c \neq 2010} \kappa_{c} \cdot D_{c}+\sum_{c \neq 2010} \beta_{c} \cdot D_{c} \cdot \text { treat }_{i}+X_{i t}^{\prime} \cdot \psi+\epsilon_{i t}
$$

where $y_{i t}^{(s)}$ is the outcome variable of interest, either for the reference individual $\left(y_{i t}\right)$ or for their spouses $\left(y_{i t}^{s}\right) . D_{c}$ are calendar year dummies, and treat $_{i}$ is an indicator for individuals in the treatment group. The matrix $X_{i t}^{\prime}$ is a set of controls that includes spousal age rounded to quarters interacted with gender when the model is estimated for spousal outcomes.

The results from these dynamic difference-in-differences (Figures 5 and 6) are discussed in detail in the next section. Note that to assess the parallel-trends assumption we must consider the pre-announcement period (2008-2010), where we find no evidence of differential trends. During the period between announcement and implementation (2011-2013) treated individuals and their spouses could adjust behaviors in anticipation of reaching increased pension eligibility ages. However, we find no evidence of anticipatory responses for the reference individuals, nor for the spouses despite a slight change in the coefficient for 2013, 
the year just before implementation. Nevertheless, to be on the safe side we quantify the

effects of the reform with respect to the pre-announcement period only, and show that our results are robust to including the anticipation period in the pre-period. Specifically, we estimate the following model to quantify the causal effects of the reform:

$$
y_{i t}^{(s)}=\beta_{0}+\beta_{1} \cdot \text { treat }_{i}+\beta_{2} \cdot \text { ant }_{i t}+\beta_{3} \cdot \text { post }_{i t}+\beta_{4} \cdot \text { treat }_{i} \cdot \text { ant }_{i t}+\beta_{5} \cdot \text { treat }_{i} \cdot \text { post }_{i t}+X_{i t}^{\prime} \cdot \psi+\epsilon_{i t}
$$

where $y_{i t}^{(s)}$ is the outcome variable of interest, either for the reference individual $\left(y_{i t}\right)$ or for their spouses $\left(y_{i t}^{s}\right)$, treat $_{i}$ is an indicator for individuals in the treatment group, ant $t_{i t}$ is an indicator for years in the anticipation period (2011-2013), post $t_{i t}$ is an indicator for implementation year 2014, and $X_{i t}^{\prime}$ is a set of controls that includes spousal age rounded to quarters interacted with spousal gender. When this equation is estimated for the reference individual, the coefficient $\beta_{5}$ identifies the causal effect of the reform on the reference individual (the first stage). When the equation is estimated for the spousal outcomes, the coefficient $\beta_{5}$ identifies the causal effect on the spouses (the reduced-form).

To obtain scaled effects for the spillover of the reform to spouses (Local Average Treatment Effects), we estimate a 2SLS model where the retirement outcomes of the reference individual are instrumented by their treatment status interacted with the calendar year where the reform directly affects them $\left(\right.$ treat $_{i} \cdot$ post $\left._{i t}\right)$. The first stage of the 2SLS model corresponds to equation (5) when it is estimated for the reference individual's outcomes. The second-stage equation is the following:

$$
y_{i t}^{s}=\beta_{0}+\beta_{1} \cdot \hat{y}_{i t}+\beta_{2} \cdot \text { treat }_{i}+\beta_{3} \cdot \text { ant }_{i t}+\beta_{4} \cdot \text { post }_{i t}+\beta_{5} \cdot \text { treat }_{i} \cdot \text { ant }_{i t}+X_{i t}^{\prime} \psi+u_{i t}
$$

where $\hat{y}_{i t}$ is the predicted outcome for the reference individual estimated in the first-stage and the coefficient $\beta_{1}$ identifies the scaled spillover effect. We show the validity of the instrument as a strong predictor of the reference individuals' outcomes in the following section. The exclusion restriction is discussed in the robustness Section 5.5 along with other specification tests.

\subsection{The Effect of Increasing the Pension Eligibility Age on Own Retirement}

The reform induced a strong response from individuals directly affected by the increase in pension eligibility ages. Figure 5 shows the results of the dynamic difference-in-differences model on the retirement outcomes of individuals directly affected by the reform. We confirm that the behavior of the treated and control groups along the three outcomes considered is 
similar during the period before announcement (2008-2010) as well as before implementation of the reform (2011-2013). The trends of both groups move in parallel and we can rule out any significant anticipatory response.

During the implementation year of 2014, individuals in the treatment group respond to the reform by delaying retirement, consistent with the strong incentives built into the VERP program. Panel (a) of Figure 5 shows that individuals in the treatment group are around 19 percentage points less likely to retire during the first half of the year. Note that the reform increased the pension eligibility age by 6 months and hence we define retirement as stopping to work during the first half of the year, as explained in Section 3. Individuals affected by the reform are also 26 percentage points less likely to claim benefits, and have higher annual labor market earnings, around $\$ 8,140$, during the implementation year. In the first row of Table 6 we report estimates from the pooled difference-in-differences model, which quantify the large and significant effect of the reform on individuals directly affected, providing a strong first stage to analyze spillover effects to spouses.

\subsection{The Effect of Increasing the Pension Eligibility Age on Spouses}

We now study the effect of the reform on spousal retirement behavior. Figure 6 reports the dynamic effects. In the period preceding the announcement of the reform (2008-2010), spouses from both treatment and control individuals behave similarly, providing evidence in support of the parallel trends assumption. After announcement and before implementation (2011-2013), no coefficient is significantly different from zero, suggesting that spouses do not respond differentially in anticipation of their partners' increased pension eligibility age, in line with the lack of anticipation of the reference individuals who are themselves affected directly by the reform. ${ }^{23}$ In the implementation year, 2014, we observe that spouses of individuals who are affected by the reform are induced to delay their retirement, consistent with extending employment in order to retire jointly with their partner. We find evidence of spouses adjusting their behavior along the other two margins as well; spouses claim later and increase their annual earnings.

The second row of Table 6 reports the difference-in-differences estimates that quantify these spousal effects. The estimates are statistically significant for retirement and claiming,

\footnotetext{
${ }^{23}$ Although we do not find evidence of anticipatory responses from spouses, we do observe that in 2013, the year just before implementation, the coefficients tend to move slightly, perhaps suggesting a mild, and not significant, anticipatory response by spouses. This is the reason why in our main model specification to quantify the effect of the reform (equations 5 and 6) we include an indicator variable for the years between announcement and anticipation of the reform.
} 
but not for earnings (\$690) due to the larger variance of this outcome. We report scaled effects from the 2SLS model in the third row of Table 6. The scaled effect on retirement is $9 \%$, indicating that for every 100 individuals who postpone their retirement due to the reform, around 9 spouses will delay their own retirement to make it coincide with that of their partner. The spillover in claiming is $4.2 \%$ and the spillover in earnings is $8.5 \%$, although the later is not statistically significant.

Overall, our findings show that the reform induced similar spillover effects as the ones we estimated in a stable context where pension eligibility ages did not change and were know by the couples well in advance. These results are consistent with a lack of significant frictions that prevent couples from adjusting their behavior to retire jointly. This may be of particular interest to policy makers trying to predict short-run responses of social security reforms based on estimates from stable settings. Conversely, it helps with interpreting other reform-based estimates in the literature, as it shows that couples' joint retirement behavior can adjust relatively quickly to changes that affect the retirement age of one partner.

We also explore heterogeneity in responses to the reform. Despite the relatively large sample size of our reform-based design (a panel of 10,321 individuals), we are unable to explore heterogeneous responses in as much depth as in the age-based design, where we estimated effects on reweighted samples and from more granular sample splits. However, the results from a simple age and gender split go in the same direction as the effect we found in the previous section using the age-based design. We report the results in Appendix Table B.1. Older spouses respond the most, with a $12 \%$ spillover in retirement against $3 \%$ for the younger spouses. The result from a simple split between male and female spouses returns estimates of similar size ( $9 \%$ and $9.1 \%$ respectively) as was the case in the age-based design. This suggest again that female spouses respond more once we account for the fact that females are most often the younger member of the couple (around 1.8 years younger in this analysis sample).

\subsection{Threats to Identification and Robustness}

Identifying assumption. The validity of our empirical approach relies on the assumption that in the absence of the reform, spousal outcomes of the treated and control individuals would move in parallel across time. We already showed that trends are parallel in the years preceding the implementation of the reform. However, in interpreting our outcomes as causal, we also assume that spouse behaviors differ in 2014 only because their partners are diferentially affected by the reform. A violation of this assumption occurs if the spouses 
themselves are directly, and differentially, impacted by the same reform.

By construction, treated individuals are 3 months older on average than control individuals, and so are their spouses. Because the reform affects individuals based on their birth date, older spouses are more likely to be directly impacted by the reform themselves. In this section we show that the differential impact of the reform on the spouses is small and that our results are robust to a series of tests that address this concern. First, note that only spouses born during the first 6 months of 1954 are affected by the reform that increases their eligibility age from 60 to $60 \frac{1}{2}$ and impacts them in 2014. In Appendix Figure B.2 we plot the distribution of spouses' birth dates and show that spouses of treated individuals are only 1.3 percentage points more likely to be born during those 6 months than spouses of control individuals (6.5\% against $5.2 \%)$.

To ensure that our results are not driven by this difference, we do the following two tests. First, we replicate our analysis reweighting the sample of treated individuals so that they have the same distribution of spousal date of birth, rounded to quarters, as the control group. The results are reported in row B of Table 7 and they are very similar to the baseline results. Second, we replicate the analysis excluding individuals whose spouses are born in the first half of 1954, both from the treatment and control groups. The results, reported in Row C, are also very similar to our baseline results.

We also note that spouses born after July 1, 1954 are affected by the reform by experiencing larger increases in their pension eligibility ages (as illustrated by Appendix Figure B.1), but these increases only affect them directly after 2014, and we do not include those years in our analysis. The differential impact of these larger increases between treatment and control spouses is 2.2 percentage points (44.3\% against $42.1 \%$ ). Importantly, this differential impact of the reform on the spouses would only affect our results if the reference individuals or their spouses responded in anticipation to future changes in their pension eligibility age. We address this concern in two ways. First, we note that across our analysis, we do not find evidence of anticipatory responses (see Figures 5 and 6). ${ }^{24}$ Second, we replicate our analysis for the subsample of individuals whose spouses are more than 3 months older. This subsample ensures that all spouses are born before January 1, 1954 and therefore are totally unaffected by the reform. The results, reported in Appendix Table B.2 show even larger spillover effects. This is to be expected, as we have shown earlier that older spouses are the ones that respond the most (see column (1) of Appendix Table B.1). Overall, these tests

\footnotetext{
${ }^{24}$ In addition, in García-Miralles and Leganza (2020) we investigate extensively the existence of anticipation responses to the reform in both labor supply and savings of individuals directly affected by the reform and do not find any.
} 
make us confident that the small share of spouses who are diferentially impacted by the reform do not have a substantive impact on our results.

Robustness. We perform a series of robustness tests including changes to the model specification and to the sample definition. Table 7 shows the results. Row $\mathrm{D}$ shows that the results are unaffected by estimating the model without the anticipation variable. Rows $\mathrm{E}$ and $\mathrm{F}$ report the results from decreasing and increasing the bandwidth around the cutoff date of January 1, 1954 by two weeks. Row G shows the results when we do not balance the sample of analysis. Row $\mathrm{H}$ adds controls for region and education of the reference individuals and their spouses, defined when they are 57 years old. Finally, row I extends the sample to include reference individuals who did not contribute to the VERP program between ages 50-59. Overall our results are robust to all these changes. We note, however, that although the size of the estimates for claiming remains remarkably stable, they turn insignificant in some cases, and the same happens to the estimates for earnings, which remain insignificant in most cases.

\section{Conclusion}

Spouses adjust their behavior to retire together, which implies a significant role for leisure complementarities within couples. We estimate joint retirement spillovers induced by pension eligibility ages in two complementary settings. In the first setting the pension eligibility age is stable and known by couples well in advance, whereas in the second setting the pension eligibility age increases due to a reform that discontinuously affects selected cohorts. We find similar joint retirement spillovers in both settings, suggesting that joint retirement behavior prevails in a reform context and is not hampered by adjustment costs. Specifically, we find that for every 100 individuals who retire upon reaching pension eligibility age, around 8 of their spouses are induced to retire as well.

Our data allow us to advance the understanding of mechanisms and behaviors that underlie joint retirement decisions. We explore different margins of adjustment such as claiming and annual earnings, and we document strong heterogeneous responses. Joint retirement is largely driven by older spouses who work past their own pension eligibility age, waiting for their younger spouses to become eligible for their own pension benefits. We uncover a significant and consistent gender gap, where female spouses are more likely to adjust their retirement age to make it coincide with that of their male partner. This gender gap emerges after controlling for the age composition of couples, since men tend to be older than females 
and this confounds the effect from a simple gender split. The gender gap is not explained by differences in relative earnings within couples. Relative earnings within couples do not seem to be major determinants of joint retirement, but we find patterns consistent with the opportunity cost of retirement.

Our results, which are derived in the context of a representative pension system, have implications for the design and evaluation of public policies. We find that policies that delay retirement ages of individuals can have spillover effects to spouses, and the size of these effects depends crucially on the age of spouses relative to their partners and on their capacity to claim benefits of their own. Our findings suggest that increasing the retirement age of younger partners (who are traditionally females) will generate the largest spillover effects in the form of delayed retirement of their older spouses. This is particularly relevant for countries whose statutory retirement ages are still lower for females. Our findings may also inform models of intra-household decision making more generally, which are increasingly the subject of theoretical and structural work on labor supply and retirement. 


\section{References}

An, M. Y., Christensen, B. J., and Gupta, N. D. (2004). Multivariate mixed proportional hazard modelling of the joint retirement of married couples. Journal of Applied Econometrics, 19(6):687-704.

Andrews, D. W. and Buchinsky, M. (2000). A three-step method for choosing the number of bootstrap repetitions. Econometrica, 68(1):23-51.

Atalay, K., Barrett, G. F., and Siminski, P. (2019). Pension incentives and the joint retirement of couples: Evidence from two natural experiments. Journal of Population Economics, 32(3):735-767.

Baker, M. (2002). The retirement behavior of married couples: Evidence from the spouse's allowance. The Journal of Human Resources, 37(1):1-34.

Banks, J., Blundell, R., and Rivas, M. C. (2010). The dynamics of retirement behavior in couples: Reduced-form evidence from England and the US . University College London, mimeo.

Behaghel, L. and Blau, D. M. (2012). Framing social security reform: Behavioral responses to changes in the full retirement age. American Economic Journal: Economic Policy, $4(4): 41-67$.

Bingley, P. and Lanot, G. (2007). Public pension programmes and the retirement of married couples in Denmark. Journal of Public Economics, 91(10):1878-1901.

Blau, D. M. (1998). Labor force dynamics of older married couples. Journal of Labor Economics, 16(3):595-629.

Bloemen, H., Hochguertel, S., and Zweerink, J. (2019). The effect of incentive-induced retirement on spousal retirement rates: Evidence from a natural experiment. Economic Inquiry, 57(2):910-930.

Casanova, M. (2010). Happy together: A structural model of couples' joint retirement choices. Working Paper, Department of Economics, University of California, (5):1-53.

Coile, C. (2004). Retirement incentives and couples' retirement decisions. Topics in Economic Analysis and Policy, 4(1):441-470.

Coile, C. and Gruber, J. (2007). Future social security entitlements and the retirement decision. The Review of Economics and Statistics, 89(2):234-246.

Cribb, J., Emmerson, C., and Tetlow, G. (2016). Signals matter? Large retirement responses to limited financial incentives. Labour Economics, 42:203-212. 
Daly, M. and Groes, F. (2017). Who takes the child to the doctor? Mom, pretty much all of the time. Applied Economics Letters, 24(17):1267-1276.

Deshpande, M., Fadlon, I., and Gray, C. (2020). How sticky is retirement behavior in the U.S.? Responses to changes in the full retirement age. NBER Working Paper No. w27190.

Fadlon, I., Ramnath, S. P., and Tong, P. K. (2019). Market inefficiency and household labor supply: Evidence from social security's survivors benefits. NBER Working Paper No. w25586.

García-Miralles, E. and Leganza, J. M. (2020). Public pensions and private savings.

Geyer, J. and Welteke, C. (2019). Closing Routes to Retirement for Women: How Do They Respond? Journal of Human Resources.

Gørtz, M., Sander, S., and Sevilla, A. (2020). Does the child penalty strike twice?

Gustman, A. L. and Steinmeier, T. L. (2000). Retirement in dual-career families: A structural model. Journal of Labor Economics, 18(3):503-545.

Gustman, A. L. and Steinmeier, T. L. (2004). Social security, pensions and retirement behaviour within the family. Journal of Applied Econometrics, 19(6):723-737.

Haller, A. (2019). Welfare effects of pension reforms.

Honoré, B. E. and de Paula, Á. (2018). A new model for interdependent durations. Quantitative Economics, 9(3):1299-1333.

Honoré, B. E., Jørgensen, T. H., and Paula, Á. (2020). The Informativeness of Estimation Moments. Journal of Applied Econometrics.

Hospido, L. and Zamarro, G. (2014). Retirement patterns of couples in Europe. IZA Journal of European Labor Studies, 3(1):12.

Hurd, M. D. (1990). The joint retirement decision of husbands and wives. In Issues in the Economics of Aging, pages 231-258. University of Chicago Press, 1990.

Kleven, H., Landais, C., and Søgaard, J. E. (2019). Children and gender inequality: Evidence from Denmark. American Economic Journal: Applied Economics, 11(4):181-209.

Kreiner, C. T., Leth-Petersen, S., and Skov, P. E. (2016). Tax reforms and intertemporal shifting of wage income: Evidence from Danish monthly payroll records. American Economic Journal: Economic Policy, 8(3):233-57.

Kruse, H. (2020). Joint retirement in couples: Evidence of complementarity in leisure. The Scandinavian Journal of Economics. 
Lalive, R. and Parrotta, P. (2017). How does pension eligibility affect labor supply in couples? Labour Economics, 46:177-188.

Lassen, A. S. (2020). Gender norms and specialization in household production: Evidence from a danish parental leave reform.

MacKinnon, J. G. (2006). Bootstrap methods in econometrics. Economic Record, 82:S2-S18.

Manoli, D. S. and Weber, A. (2016). The effects of the early retirement age on retirement decisions. NBER Working Paper No. w22561.

Mastrobuoni, G. (2009). Labor supply effects of the recent social security benefit cuts: Empirical estimates using cohort discontinuities. Journal of Public Economics, 93(1112):1224-1233.

Michaud, P.-C. and Vermeulen, F. (2011). A collective labor supply model with complementarities in leisure: Identification and estimation by means of panel data. Labour Economics, 18(2):159-167.

Nakazawa, N. (2019). The effects of increasing the eligibility age for public pension on individual labor supply: Evidence from Japan. Available at SSRN 3438100.

Nielsen, N. F. (2019). Sick of retirement? Journal of Health Economics, 65:133-152.

OECD (2015). Pensions at a Glance: OECD and G20 Indicators. OECD.

OECD (2017). Pensions at a Glance: OECD and G20 Indicators. OECD.

OECD (2019). Pensions at a Glance: OECD and G20 Indicators. OECD.

Selin, H. (2017). What happens to the husband's retirement decision when the wife's retirement incentives change? International Tax and Public Finance, 24(3):432-458.

Stancanelli, E. (2017). Couples' retirement under individual pension design: A regression discontinuity study for France. Labour Economics, 49:14-26.

Staubli, S. and Zweimüller, J. (2013). Does raising the early retirement age increase employment of older workers? Journal of Public Economics, 108:17-32.

Van der Klaauw, W. and Wolpin, K. I. (2008). Social security and the retirement and savings behavior of low-income households. Journal of Econometrics, 145(1-2):21-42. 
Figure 1: The Effect of Reaching Pension Eligibility Age on Own Retirement

(a) Retirement

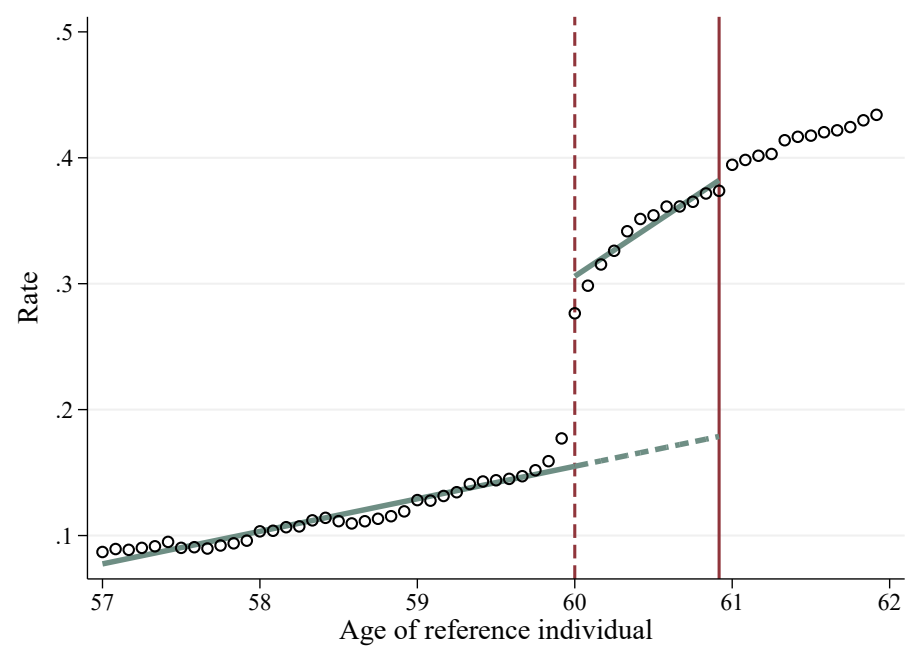

(b) Claiming

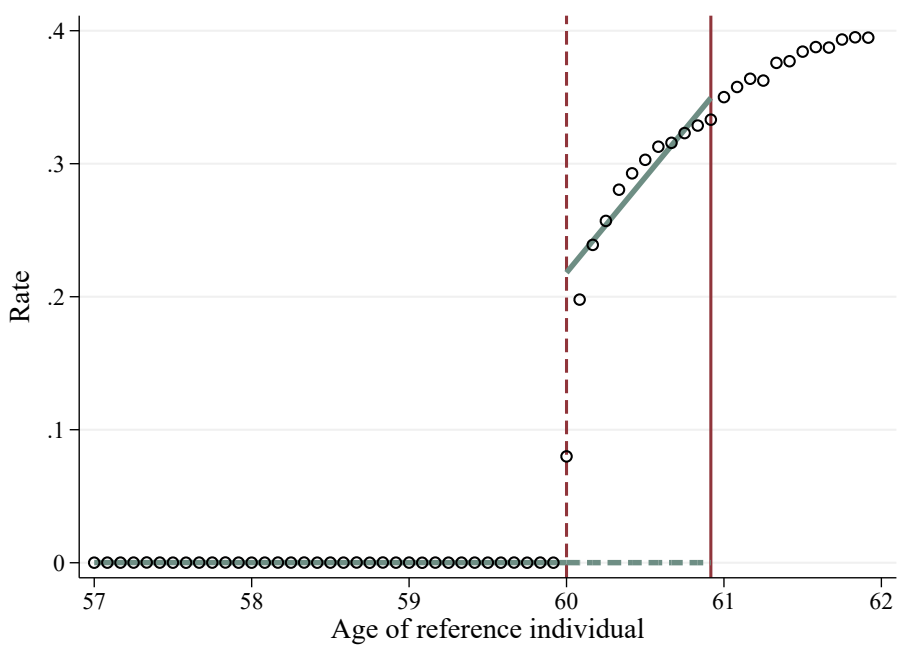

(c) Earnings

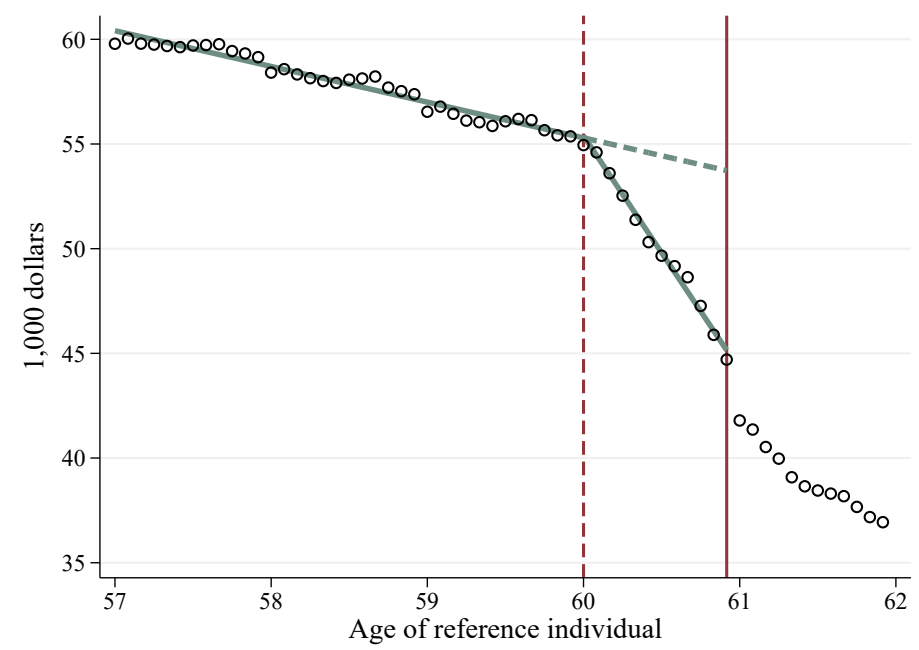

Notes: These figures plot different outcomes for individuals around their own pension eligibility age of 60, pooling individuals over the period 1991-2013. The hollow circles are raw means of the outcome variable measured at the end of each calendar year, grouped in monthly age bins. The solid lines plot the parametric fit estimated with the piecewise linear regression model (1). The dashed line represents the counterfactual behavior in the absence of pension eligibility, based on a linear extrapolation from the observed outcome before age 60 . The full-exposure effect of being eligible for early retirement pension during an entire year is represented by the vertical distance between the solid and dashed lines just below age 61 . 
Figure 2: The Effect of Reaching Pension Eligibility Age on Spouses

(a) Spouse Retirement

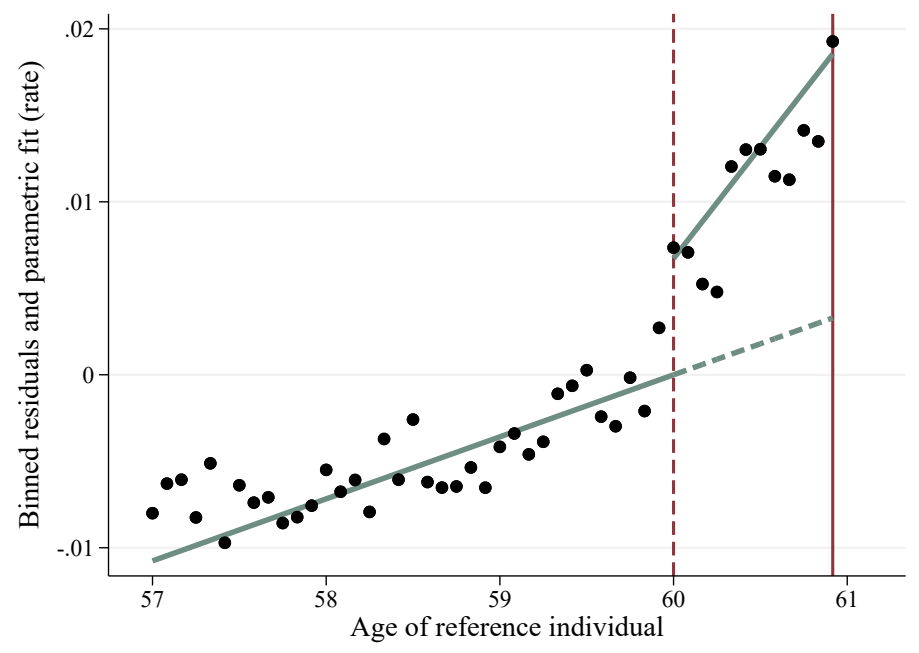

(b) Spouse Claiming

(c) Spouse Earnings
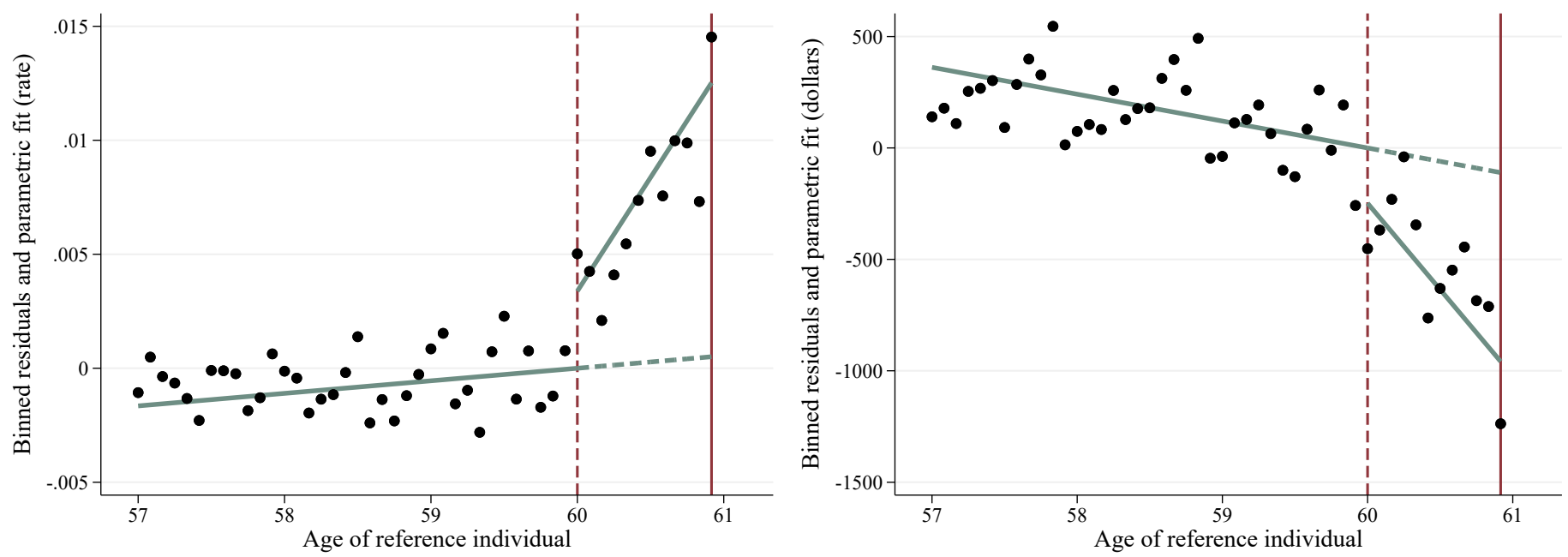

Notes: These figures plot different outcomes for spouses around the pension eligibility age of their partner. The dots are the residuals estimated in equation (2) where the spousal outcome is regressed on their own age and gender. The residuals are grouped in monthly bins of the reference individual's age. The solid lines plot the parametric fit estimated with the piecewise linear regression model (3). The dashed line represents the counterfactual behavior in the absence of pension eligibility, based on a linear extrapolation from the observed outcome before age 60 . The full-exposure effect on the spouses of their partners being eligible for early retirement pension during an entire year is represented by the vertical distance between the solid and dashed lines just below age 61 . 
Figure 3: Joint Retirement Behavior by Age Differences Within Couples

(a) Retirement

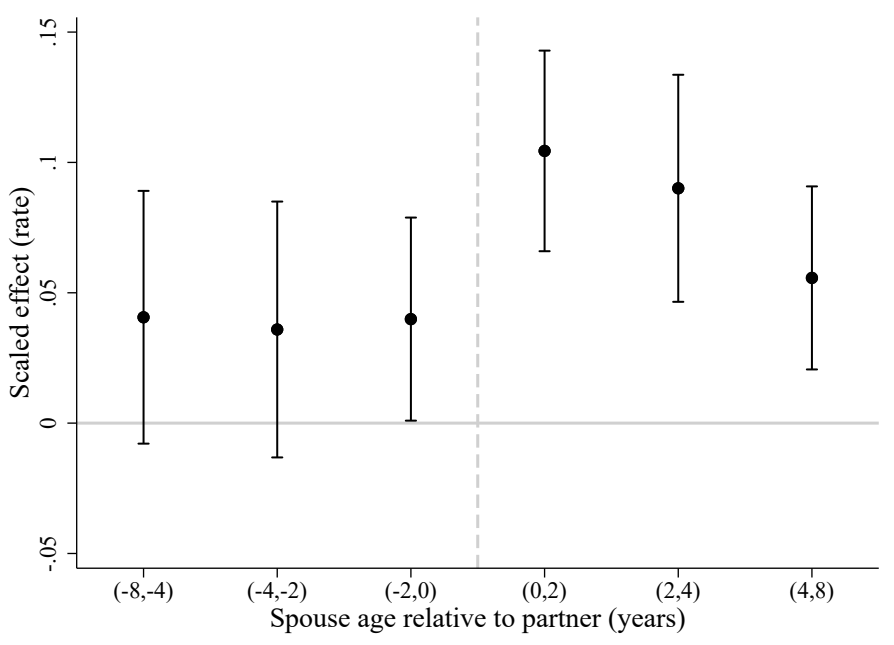

(b) Claiming

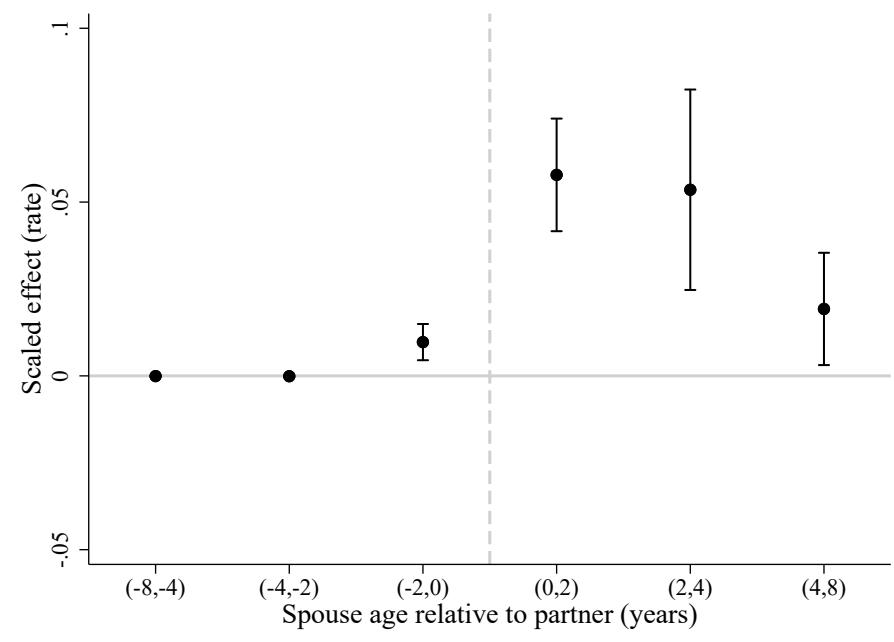

(c) Earnings

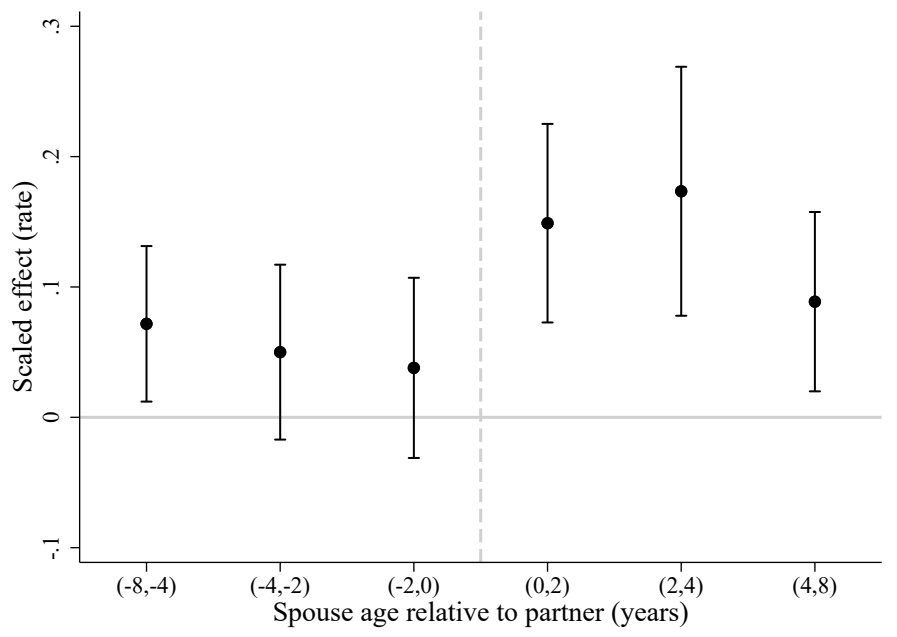

Notes: These figures plot the scaled estimates of joint retirement for different subsamples of couples based on the age difference between spouses. These scaled effects are estimated using the same methodology as for the full sample: first estimating models (1) and (3) to obtain full-exposure effects and then dividing the full-exposure effect on spouses by the full-exposure effect on reference individuals. We report $95 \%$ confidence intervals calculated from bootstrapped standard errors. 
Figure 4: The Evolution of Joint Retirement Over Time

(a) Retirement

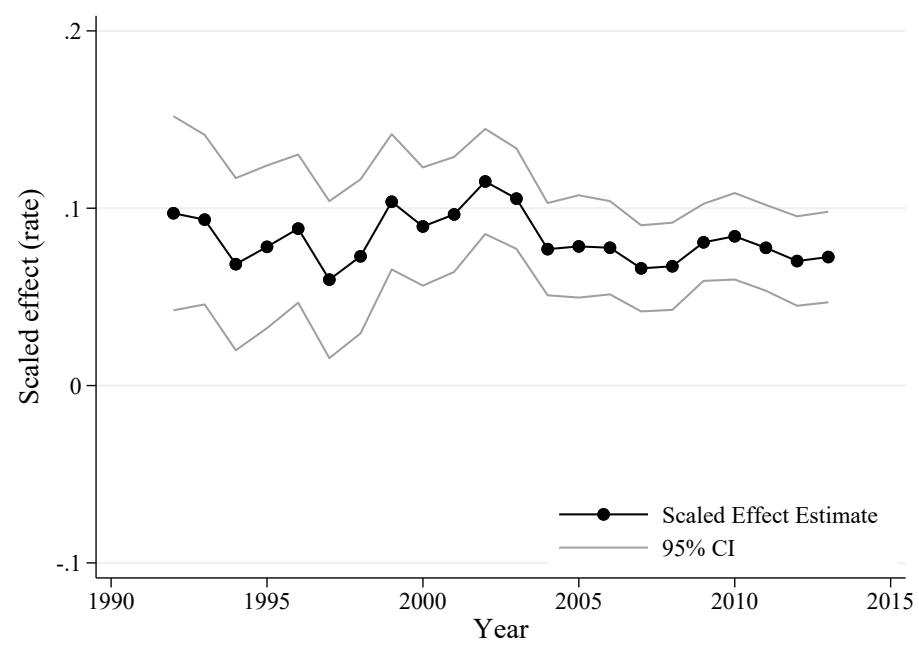

(b) Claiming

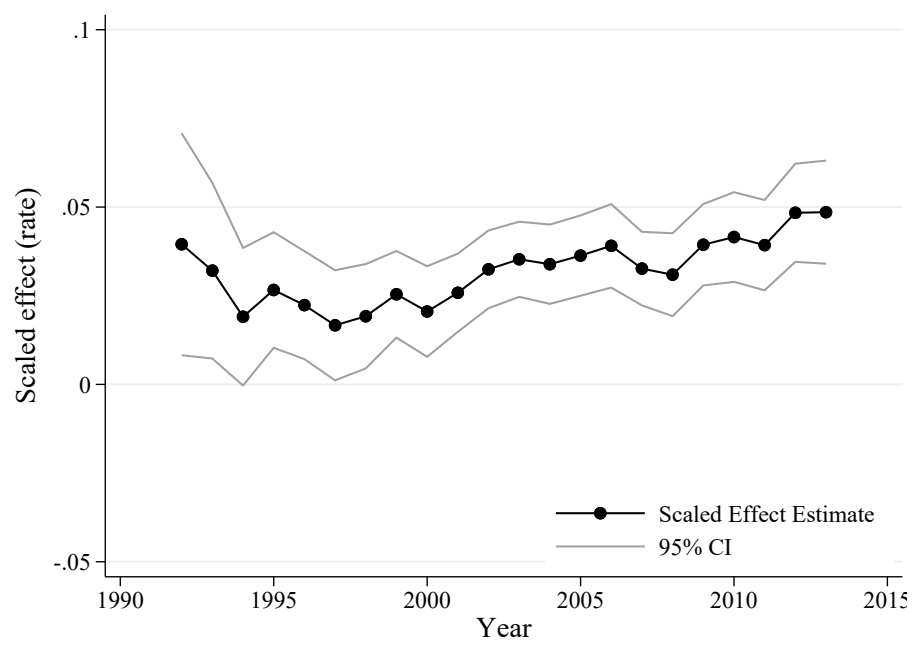

(c) Earnings

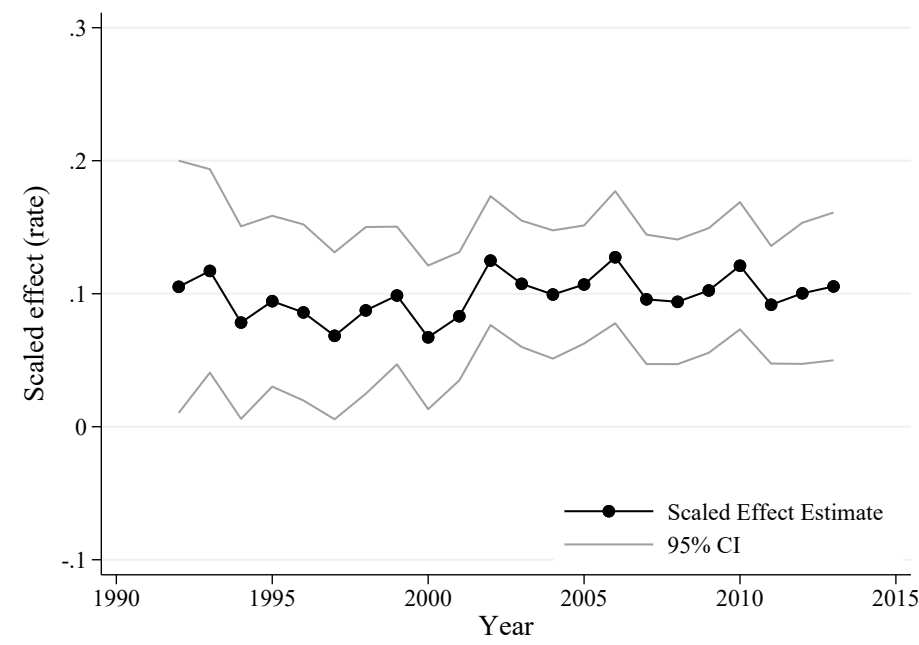

Notes: These figures plot the evolution over time of the scaled estimates of joint retirement for different outcomes. Scaled effects are estimated over a 5-year running window using the same methodology as for the full time period: first estimating models (1) and (3) to obtain full-exposure effects and then dividing the full-exposure effect on spouses by the full-exposure effect on reference individuals. Appendix Figure A.5 reports these full-exposure effects over time for the retirement outcome. The scaled effects and the full-exposure effects for the whole period 1991-2013 are reported in Table 2. We report 95\% confidence intervals calculated from bootstrapped standard errors. 
Figure 5: The Effect of Increasing Pension Eligibility Age on Own Retirement

(a) Retirement

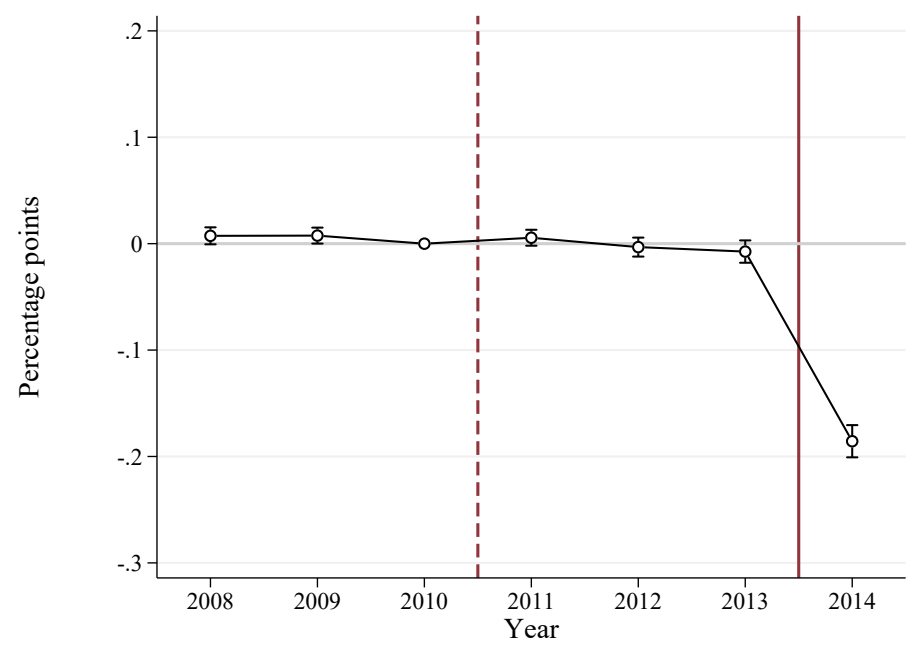

(b) Claiming

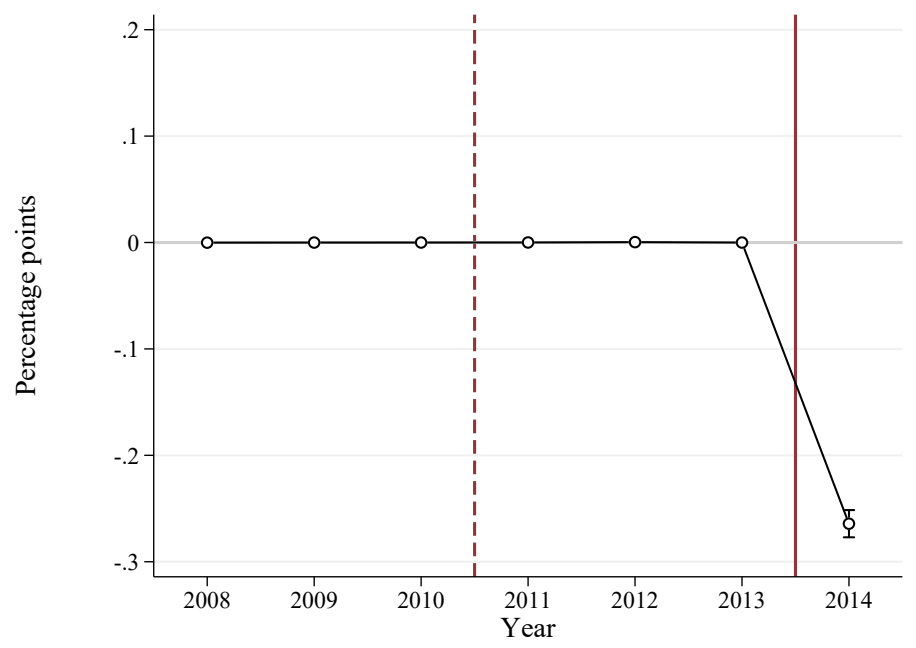

(c) Earnings

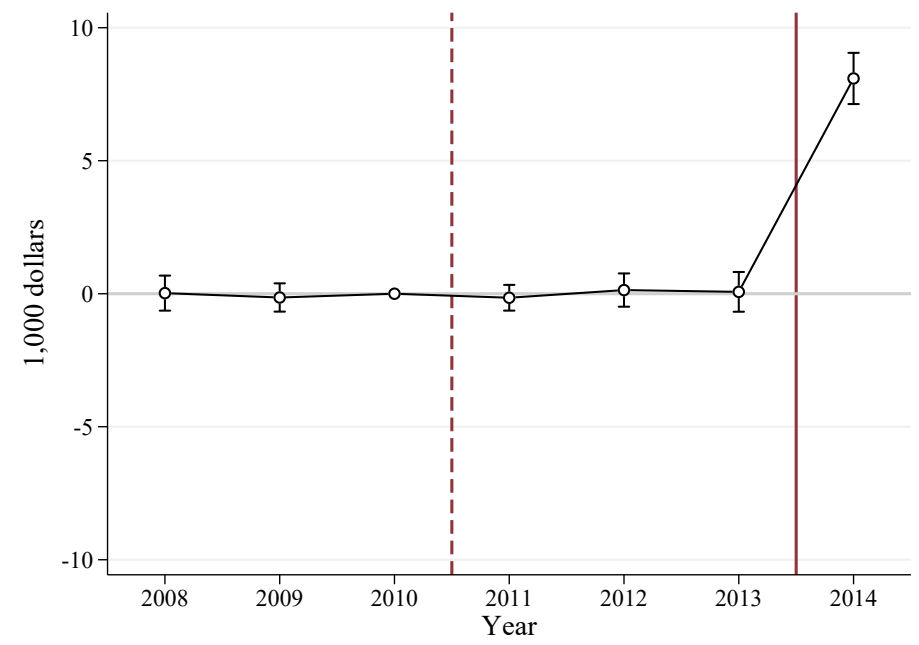

Notes: These figures plot the $\beta_{c}$ coefficients from the dynamic difference-in-differences model (4), estimated on different outcomes for reference individuals. Each coefficient shows the difference between the treated group (whose pension eligibility age increases by 6 months, to age $60 \frac{1}{2}$ ) and the control group (whose pension eligibility age remains at age 60). Individuals turn 60 around the beginning of 2014, therefore the coefficient for 2014 identifies the causal effect of the reform during the implementation year. We report confidence intervals at the $95 \%$ level, calculated from robust standard errors clustered at the couple level. 
Figure 6: The Effect of Increasing Pension Eligibility Age on Spouses

(a) Spouse Retirement

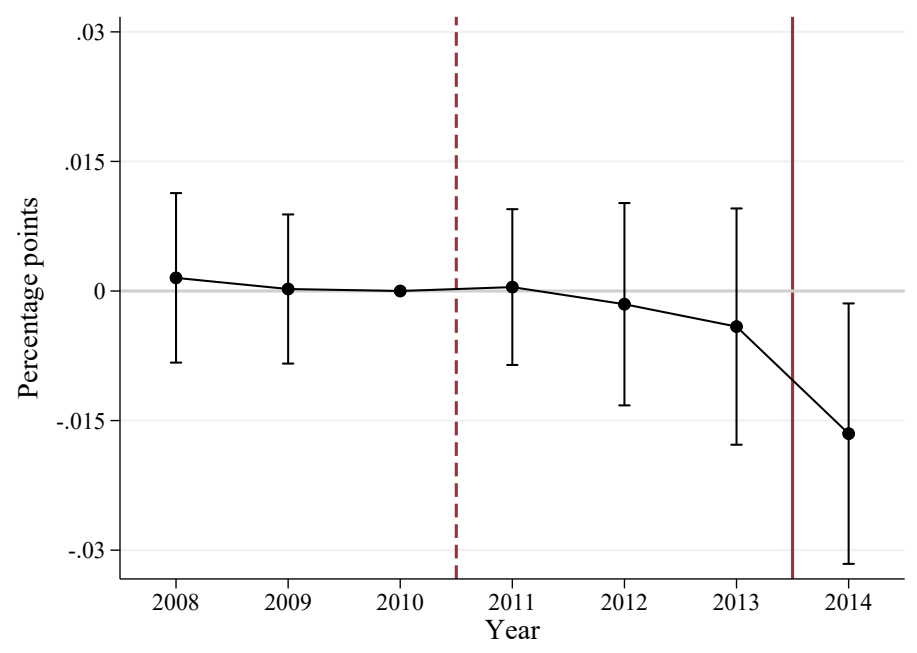

(b) Spouse Claiming

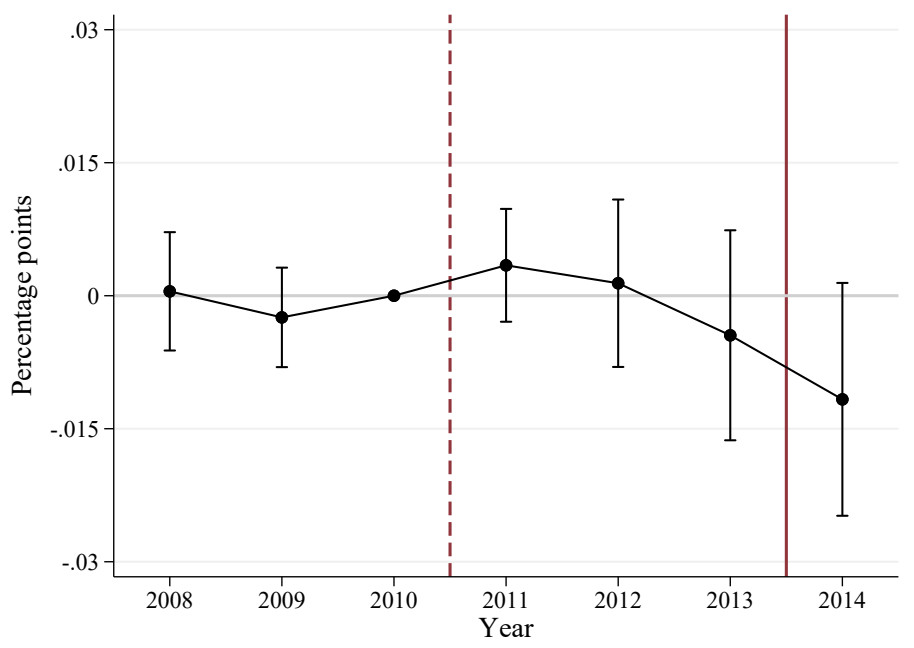

(c) Spouse Earnings

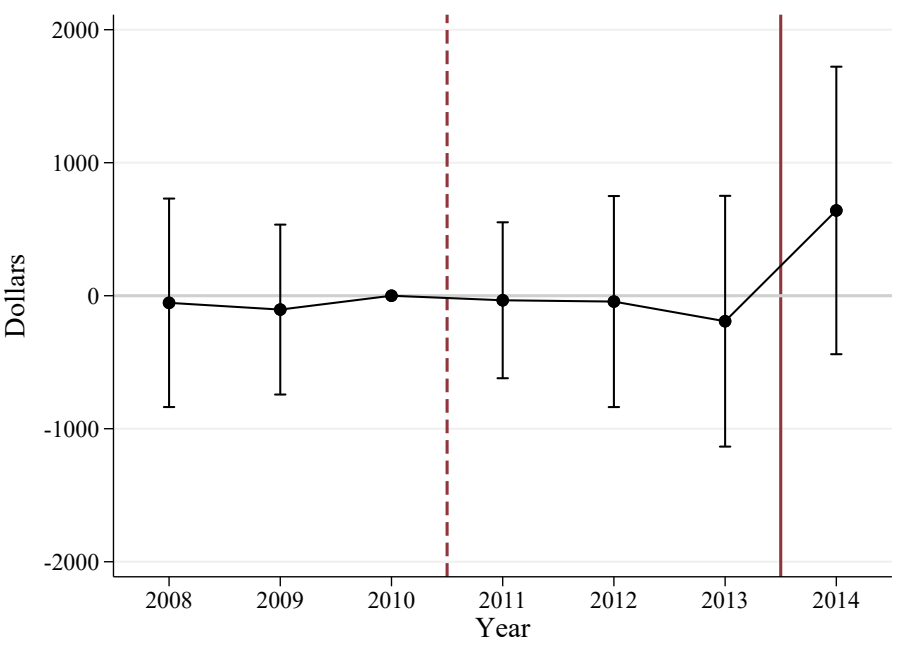

Notes: These figures plot the $\beta_{c}$ coefficients from the dynamic difference-in-differences model from equation (4), estimated on different outcomes for spouses of reference individuals. Each coefficient shows the difference between the treatment group (spouses whose partners' pension eligibility age increases by 6 months, to age $60 \frac{1}{2}$ ) and the control group (spouses whose partners' pension eligibility age remains at 60 ). The coefficient for 2014 identifies the causal effect of the reform on the spouses on the implementation year. We report confidence intervals at the $95 \%$ level, calculated from robust standard errors clustered at the couple level. 
Table 1: Summary Statistics

\begin{tabular}{|c|c|c|c|c|c|c|c|c|}
\hline & \multicolumn{4}{|c|}{$\begin{array}{c}\text { Age-Based Design Period } \\
(1991-2013)\end{array}$} & \multicolumn{4}{|c|}{$\begin{array}{c}\text { Reform-Based Design Period } \\
(2008-2014) \\
\end{array}$} \\
\hline & \multicolumn{2}{|c|}{ Population } & \multicolumn{2}{|c|}{ Analysis Sample } & \multicolumn{2}{|c|}{ Population } & \multicolumn{2}{|c|}{ Analysis Sample } \\
\hline & $\begin{array}{c}\text { Mean } \\
(1)\end{array}$ & $\begin{array}{l}\mathrm{SD} \\
(2)\end{array}$ & $\begin{array}{c}\text { Mean } \\
(3)\end{array}$ & $\begin{array}{l}\mathrm{SD} \\
(4)\end{array}$ & $\begin{array}{c}\text { Mean } \\
(5)\end{array}$ & $\begin{array}{l}\mathrm{SD} \\
(6)\end{array}$ & $\begin{array}{c}\text { Mean } \\
(7)\end{array}$ & $\begin{array}{l}\mathrm{SD} \\
(8)\end{array}$ \\
\hline \multicolumn{9}{|c|}{ A: Reference Individuals } \\
\hline Age & 58.45 & 1.12 & 58.44 & 1.12 & 57.45 & 2.04 & 57.47 & 2.06 \\
\hline Male & 0.51 & 0.50 & 0.52 & 0.50 & 0.50 & 0.50 & 0.47 & 0.50 \\
\hline Dane & 0.98 & 0.15 & 1.00 & 0.00 & 0.97 & 0.18 & 1.00 & 0.00 \\
\hline Copenhagen region & 0.26 & 0.44 & 0.27 & 0.44 & 0.25 & 0.43 & 0.22 & 0.41 \\
\hline Educ. Primary & 0.37 & 0.48 & 0.29 & 0.45 & 0.30 & 0.46 & 0.25 & 0.43 \\
\hline Educ. Secondary & 0.41 & 0.49 & 0.45 & 0.50 & 0.41 & 0.49 & 0.45 & 0.50 \\
\hline Educ. Tertiary & 0.03 & 0.18 & 0.04 & 0.19 & 0.04 & 0.20 & 0.04 & 0.20 \\
\hline Educ. Bachelor & 0.14 & 0.34 & 0.17 & 0.37 & 0.18 & 0.39 & 0.20 & 0.40 \\
\hline Educ. Master & 0.05 & 0.22 & 0.05 & 0.22 & 0.07 & 0.26 & 0.05 & 0.23 \\
\hline Earnings age $55-57$ & 45,268 & 41,165 & 60,289 & 35,186 & 55,582 & 41,780 & 64,156 & 32,218 \\
\hline Retired by age 57 & 0.20 & 0.40 & 0.09 & 0.29 & 0.25 & 0.43 & 0.12 & 0.32 \\
\hline Retired by age 58 & 0.22 & 0.41 & 0.11 & 0.31 & 0.26 & 0.44 & 0.13 & 0.34 \\
\hline Retired by age 59 & 0.24 & 0.43 & 0.14 & 0.35 & 0.29 & 0.45 & 0.16 & 0.37 \\
\hline Retired by age 60 & 0.39 & 0.49 & 0.34 & 0.47 & 0.43 & 0.49 & 0.35 & 0.48 \\
\hline \multicolumn{9}{|l|}{ B: Spouses } \\
\hline Age difference (years) & 0.34 & 5.23 & 0.25 & 3.46 & 0.19 & 5.26 & -0.10 & 3.50 \\
\hline Age & 58.11 & 5.36 & 58.19 & 3.64 & 57.26 & 5.62 & 57.57 & 4.04 \\
\hline Male & 0.49 & 0.50 & 0.48 & 0.50 & 0.50 & 0.50 & 0.53 & 0.50 \\
\hline Dane & 0.99 & 0.08 & 1.00 & 0.06 & 0.98 & 0.12 & 0.99 & 0.08 \\
\hline Copenhagen region & 0.26 & 0.44 & 0.27 & 0.44 & 0.25 & 0.43 & 0.22 & 0.41 \\
\hline Educ. Primary & 0.37 & 0.48 & 0.29 & 0.46 & 0.28 & 0.45 & 0.23 & 0.42 \\
\hline Educ. Secondary & 0.41 & 0.49 & 0.44 & 0.50 & 0.42 & 0.49 & 0.45 & 0.50 \\
\hline Educ. Tertiary & 0.03 & 0.18 & 0.04 & 0.19 & 0.04 & 0.21 & 0.05 & 0.23 \\
\hline Educ. Bachelor & 0.14 & 0.35 & 0.17 & 0.38 & 0.18 & 0.39 & 0.20 & 0.40 \\
\hline Educ. Master & 0.05 & 0.22 & 0.05 & 0.22 & 0.07 & 0.26 & 0.06 & 0.24 \\
\hline Earnings age $55-57$ & 45,877 & 39,995 & 58,419 & 34,725 & 56,091 & 43,924 & 66,224 & 34,921 \\
\hline Retired by age 57 & 0.20 & 0.40 & 0.12 & 0.33 & 0.26 & 0.44 & 0.15 & 0.36 \\
\hline Retired by age 58 & 0.21 & 0.41 & 0.13 & 0.34 & 0.26 & 0.44 & 0.14 & 0.35 \\
\hline Retired by age 59 & 0.22 & 0.42 & 0.15 & 0.35 & 0.26 & 0.44 & 0.15 & 0.35 \\
\hline Retired by age 60 & 0.34 & 0.48 & 0.30 & 0.46 & 0.35 & 0.48 & 0.27 & 0.44 \\
\hline Number of Observations & \multicolumn{2}{|c|}{$4,366,996$} & \multicolumn{2}{|c|}{$2,206,044$} & \multicolumn{2}{|c|}{166,554} & \multicolumn{2}{|c|}{73,395} \\
\hline
\end{tabular}

Notes: This table reports means and standard deviations of relevant variables for different samples of interest. The first four columns correspond to the age-based period of analysis (1991-2013) where the pension eligibility age remained stable, and it includes individuals of age 57 to 60 . The last four columns correspond to the reformbased period of analysis (2008-2014) where the pension eligibility age was increased starting in 2014, and it includes individuals born between July 1, 1953 and June 30, 1954. Columns denoted "Population" correspond to the full population without applying any sample restriction. Columns denoted "Analysis sample" correspond to our baseline samples of analysis, after applying the restrictions described in Section 3.3. 
Table 2: The Effect of Reaching Pension Eligibility Age

\begin{tabular}{lccc}
\hline & Retirement & Claiming & Earnings \\
\hline \hline Reference Individual & $0.2034^{* * *}$ & $0.3496^{* * *}$ & $-8,642^{* * *}$ \\
& $(0.001)$ & $(0.001)$ & $(69.431)$ \\
Spouse & $0.0153^{* * *}$ & $0.0120^{* * *}$ & $-848^{* * *}$ \\
& $(0.001)$ & $(0.001)$ & $(61.165)$ \\
Scaled Effect & $0.0750^{* * *}$ & $0.0344^{* * *}$ & $0.0981^{* * *}$ \\
& $(0.0071)$ & $(0.0031)$ & $(0.012)$ \\
\hline \hline N. of clusters & 367,585 & 367,585 & 367,585 \\
Observations & $2,206,044$ & $2,206,044$ & $2,206,044$ \\
\hline
\end{tabular}

Notes: This table reports the effect of reference individuals reaching pension eligibility age on their own retirement and on their spouses' retirement. Each column reports the results for a different outcome. The first row reports the full-exposure effect to pension eligibility on own retirement estimated in equation (1). The second row reports the full-exposure effect on the spouses from their partners becoming eligible for pension, estimated in equation (3). The third row reports the scaled effect resulting from diving the spouse full-exposure effect by the reference individual full-exposure effect. Robust standard errors in parentheses, clustered at the couple level. Bootstrapped standard errors for scaled effects. ${ }^{* * *} p<0.01$, ${ }^{* *} p<0.05,{ }^{*} p<0.1$ 
Table 3: Heterogeneity in the Effect of Reaching Pension Eligibility Age on Retirement by Age Difference and Gender

\begin{tabular}{|c|c|c|c|c|c|c|}
\hline Reference Individual & Young & Old & Female & Male & Male (w) & Male (w) \\
\hline Spouse & $\begin{array}{l}\text { Old } \\
\qquad(1)\end{array}$ & $\begin{array}{c}\text { Young } \\
(2)\end{array}$ & $\begin{array}{r}\text { Male } \\
(3)\end{array}$ & $\begin{array}{c}\text { Female } \\
(4)\end{array}$ & $\begin{array}{l}\text { Female }(\mathrm{w}) \\
(5)\end{array}$ & $\begin{array}{l}\text { Female }(\mathrm{w}) \\
\quad(6)\end{array}$ \\
\hline \multicolumn{7}{|l|}{ A. Retirement } \\
\hline Reference Individual & $\begin{array}{l}0.2562^{* * *} \\
(0.002)\end{array}$ & $\begin{array}{l}0.1588^{* * *} \\
(0.002)\end{array}$ & $\begin{array}{l}0.2668^{* * *} \\
(0.002)\end{array}$ & $\begin{array}{l}0.1479^{* * *} \\
(0.001)\end{array}$ & $\begin{array}{l}0.1616^{* * *} \\
(0.002)\end{array}$ & $\begin{array}{l}0.1795^{\text {*** }} \\
(0.003)\end{array}$ \\
\hline Spouse & $\begin{array}{l}0.026^{* * *} \\
(0.002)\end{array}$ & $\begin{array}{l}0.004^{* * *} \\
(0.001)\end{array}$ & $\begin{array}{l}0.020^{* * *} \\
(0.001)\end{array}$ & $\begin{array}{l}0.011^{\text {*** }} \\
(0.002)\end{array}$ & $\begin{array}{l}0.021^{* * *} \\
(0.002)\end{array}$ & $\begin{array}{l}0.024^{* * *} \\
(0.003)\end{array}$ \\
\hline Scaled Effect & $\begin{array}{l}0.0994^{* * *} \\
(0.0088)\end{array}$ & $\begin{array}{l}0.0287^{* * *} \\
(0.010)\end{array}$ & $\begin{array}{l}0.0745^{* * *} \\
(0.0070)\end{array}$ & $\begin{array}{l}0.0751^{* * *} \\
(0.013)\end{array}$ & $\begin{array}{l}0.130^{* * *} \\
(0.018)\end{array}$ & $\begin{array}{l}0.136^{* * *} \\
(0.017)\end{array}$ \\
\hline \multicolumn{7}{|l|}{ B. Claiming } \\
\hline Reference Individual & $\begin{array}{l}0.4307^{* * *} \\
(0.002)\end{array}$ & $\begin{array}{l}0.28^{* * *} \\
(0.002)\end{array}$ & $\begin{array}{l}0.4567^{* * *} \\
(0.002)\end{array}$ & $\begin{array}{l}0.2544^{* * *} \\
(0.002)\end{array}$ & $\begin{array}{l}0.2632^{\text {*** }} \\
(0.002)\end{array}$ & $\begin{array}{l}0.295^{* * *} \\
(0.003)\end{array}$ \\
\hline Spouse & $\begin{array}{l}0.021^{* * *} \\
(0.002)\end{array}$ & $\begin{array}{l}0.000 \\
(0.000)\end{array}$ & $\begin{array}{l}0.017^{* * *} \\
(0.001)\end{array}$ & $\begin{array}{l}0.008^{* * *} \\
(0.001)\end{array}$ & $\begin{array}{l}0.018^{* * *} \\
(0.002)\end{array}$ & $\begin{array}{l}0.020^{* * *} \\
(0.003)\end{array}$ \\
\hline Scaled Effect & $\begin{array}{l}0.0495^{* * *} \\
(0.0053)\end{array}$ & $\begin{array}{l}0.00350^{* * *} \\
(0.0010)\end{array}$ & $\begin{array}{l}0.0374^{* * *} \\
(0.0044)\end{array}$ & $\begin{array}{l}0.0301^{* * *} \\
(0.0038)\end{array}$ & $\begin{array}{l}0.0674^{* * *} \\
(0.0092)\end{array}$ & $\begin{array}{l}0.0691^{\text {*** }} \\
(0.010)\end{array}$ \\
\hline \multicolumn{7}{|l|}{ C. Earnings } \\
\hline Reference Individual & $\begin{array}{l}-9,558^{* * *} \\
(93.657)\end{array}$ & $\begin{array}{l}-7,970^{* * *} \\
(97.971)\end{array}$ & $\begin{array}{l}-9,081^{* * *} \\
(81.417)\end{array}$ & $\begin{array}{l}-8,408^{* * *} \\
(104.024)\end{array}$ & $\begin{array}{l}-9,035^{* * *} \\
(140.987)\end{array}$ & $\begin{array}{c}-9,160^{* * *} \\
(162.946)\end{array}$ \\
\hline Spouse & $\begin{array}{l}-1,856^{* * *} \\
(117.525)\end{array}$ & $\begin{array}{l}-510^{* * *} \\
(79.457)\end{array}$ & $\begin{array}{l}-1,168^{* * *} \\
(160.724)\end{array}$ & $\begin{array}{l}-602^{* * *} \\
(68.661)\end{array}$ & $\begin{array}{l}-589^{* * *} \\
(97.229)\end{array}$ & $\begin{array}{l}-769^{* * *} \\
(151.466)\end{array}$ \\
\hline Scaled Effect & $\begin{array}{l}0.184^{* * *} \\
(0.020)\end{array}$ & $\begin{array}{l}0.0608^{* * *} \\
(0.017)\end{array}$ & $\begin{array}{l}0.122^{* * *} \\
(0.021)\end{array}$ & $\begin{array}{l}0.0680^{* * *} \\
(0.014)\end{array}$ & $\begin{array}{l}0.0661^{* * *} \\
(0.018)\end{array}$ & $\begin{array}{l}0.0849^{* * *} \\
(0.025)\end{array}$ \\
\hline N. of clusters & 297,686 & 334,966 & 302,589 & 330,172 & 330,172 & 330,172 \\
\hline Observations & $1,038,096$ & $1,167,948$ & $1,054,359$ & $1,151,685$ & $1,151,685$ & $1,151,685$ \\
\hline
\end{tabular}

Notes: This table reports the effect of the reference individuals reaching pension eligibility age on their own retirement and on their spouses' retirement, distinguishing heterogeneous responses by gender and age differences within the couple. Each column shows results for a different subsample. The subsample in column (5) is reweighted to have the same distribution of age differences as the subsample from column (3) and the subsample in column (6) is further reweighted to have the same distribution of earnings shares as (3). Each panel reports results for a different outcome variable. Within each panel, the first row reports the full-exposure effect of pension eligibility on own retirement. The second row reports the full-exposure effect on spouses of their partners being eligible for retirement pension. The third row reports the scaled effect resulting from diving the spouse full-exposure effect by the reference individual full-exposure effect. Robust standard errors in parentheses, clustered at the couple level. Bootstrapped standard errors for scaled effects. ${ }^{* * *} p<0.01,{ }^{* *} p<0.05,{ }^{*} p<0.1$ 
Table 4: Heterogeneity in the Effect of Reaching Pension Eligibility Age on Retirement by Primary vs Secondary Earner Status

\begin{tabular}{lcccc}
\hline Reference Individual & Young Primary & Young Sec. (w) & Old Primary & Old Second. (w) \\
Spouse & Old Secondary & Old Prim. (w) & Young Secondary & Young Prim. (w) \\
& $(1)$ & $(2)$ & $(3)$ & $(4)$ \\
\hline
\end{tabular}

\begin{tabular}{|c|c|c|c|c|}
\hline \multicolumn{5}{|l|}{ A. Retirement } \\
\hline Reference Individual & $\begin{array}{l}0.2094^{* * *} \\
(0.003)\end{array}$ & $\begin{array}{l}0.2651^{* * *} \\
(0.003)\end{array}$ & $\begin{array}{l}0.1412^{* * *} \\
(0.002)\end{array}$ & $\begin{array}{l}0.1541^{* * *} \\
(0.004)\end{array}$ \\
\hline Spouse & $\begin{array}{l}0.0197^{* * *} \\
(0.003)\end{array}$ & $\begin{array}{l}0.028^{* * *} \\
(0.002)\end{array}$ & $\begin{array}{l}0.0073^{* * *} \\
(0.002)\end{array}$ & $\begin{array}{l}0.004 \\
(0.002)\end{array}$ \\
\hline Scaled effect & $\begin{array}{l}0.0928^{* * *} \\
(0.022)\end{array}$ & $\begin{array}{l}0.104^{* * *} \\
(0.014)\end{array}$ & $\begin{array}{l}0.0537^{* * *} \\
(0.019)\end{array}$ & $\begin{array}{l}0.0265 \\
(0.023)\end{array}$ \\
\hline \multicolumn{5}{|l|}{ B. Claiming } \\
\hline Reference Individual & $\begin{array}{l}0.3093^{* * *} \\
(0.003)\end{array}$ & $\begin{array}{l}0.5011^{* * *} \\
(0.003)\end{array}$ & $\begin{array}{l}0.2200^{* * *} \\
(0.002)\end{array}$ & $\begin{array}{l}0.4015^{\text {*** }} \\
(0.005)\end{array}$ \\
\hline Spouse & $\begin{array}{l}0.0133^{* * *} \\
(0.003)\end{array}$ & $\begin{array}{l}0.029^{* * *} \\
(0.002)\end{array}$ & $\begin{array}{l}0.0003 \\
(0.000)\end{array}$ & $\begin{array}{l}0.000 \\
(0.001)\end{array}$ \\
\hline Scaled effect & $\begin{array}{l}0.0430^{* * *} \\
(0.014)\end{array}$ & $\begin{array}{l}0.0576^{* * *} \\
(0.0070)\end{array}$ & $\begin{array}{l}0.00481^{* *} \\
(0.0019)\end{array}$ & $\begin{array}{l}0.00235 \\
(0.0018)\end{array}$ \\
\hline \multicolumn{5}{|l|}{ C. Earnings } \\
\hline Reference Individual & $\begin{array}{l}-9,454^{* * *} \\
(197.6)\end{array}$ & $\begin{array}{l}-9,366^{* * *} \\
(116.7)\end{array}$ & $\begin{array}{l}-7,915^{* * *} \\
(137.0)\end{array}$ & $\begin{array}{l}-8,797^{* * *} \\
(223.7)\end{array}$ \\
\hline Spouse & $\begin{array}{c}-754^{* * *} \\
(155.4)\end{array}$ & $\begin{array}{l}-1,056^{* * *} \\
(178.9)\end{array}$ & $\begin{array}{l}-672^{* * *} \\
(87.2)\end{array}$ & $\begin{array}{l}-1,586^{* * *} \\
(195.6)\end{array}$ \\
\hline Scaled effect & $\begin{array}{l}0.0819^{* * *} \\
(0.026)\end{array}$ & $\begin{array}{l}0.115^{* * *} \\
(0.033)\end{array}$ & $\begin{array}{l}0.0855^{* * *} \\
(0.021)\end{array}$ & $\begin{array}{l}0.181^{* * *} \\
(0.035)\end{array}$ \\
\hline $\begin{array}{l}\text { N. of clusters } \\
\text { Observations }\end{array}$ & $\begin{array}{l}94,735 \\
321,816\end{array}$ & $\begin{array}{l}161,573 \\
571,978\end{array}$ & $\begin{array}{l}193,106 \\
671,295\end{array}$ & $\begin{array}{l}93,917 \\
327752\end{array}$ \\
\hline Observations & 321,816 & 571,978 & 671,295 & 327,752 \\
\hline
\end{tabular}

Notes: The table reports the effect of the reference individuals reaching pension eligibility age on their own retirement and on their spouses' retirement, distinguishing heterogeneous responses by primary earner status within the couple. Each column contains results for a subsample of the population by age and earnings differences within couples. The subsamples in columns (2) and (4) are reweighed to have the same distribution of gender and age differences as columns (1) and (3), respectively. Each panel reports results for a different outcome variable. Within each panel, the first row reports the full-exposure effect of pension eligibility on own retirement. The second row reports the full exposure-effect on spouses of their partners being eligible for retirement pension. The third row reports the scaled effect resulting from diving the spouse full-exposure effect by the reference individual full-exposure effect. Robust standard errors in parentheses, clustered at the couple level. ${ }^{* * *} p<0.01,{ }^{* *} p<0.05,{ }^{*} p<0.1$ 
Table 5: Robustness to Alternative Specifications for the Effect of Reaching Pension Eligibility Age

\begin{tabular}{|c|c|c|c|}
\hline & Retirement & Claiming & Earnings \\
\hline A. Baseline & $\begin{array}{c}0.0750^{* * *} \\
(0.0071)\end{array}$ & $\begin{array}{c}0.0344^{* * *} \\
(0.0031)\end{array}$ & $\begin{array}{c}0.0981^{* * *} \\
(0.012)\end{array}$ \\
\hline B. Including Younger Ages & $\begin{array}{c}0.0752^{* * *} \\
(0.0052)\end{array}$ & $\begin{array}{c}0.0360^{* * *} \\
(0.0026)\end{array}$ & $\begin{array}{c}0.0934^{* * *} \\
(0.010)\end{array}$ \\
\hline C. Excluding Age 59 & $\begin{array}{c}0.0904^{* * *} \\
(0.011)\end{array}$ & $\begin{array}{c}0.0387^{* * *} \\
(0.0047)\end{array}$ & $\begin{array}{c}0.120^{* * *} \\
(0.018)\end{array}$ \\
\hline D. No Donut December & $\begin{array}{c}0.0730^{* * *} \\
(0.0068)\end{array}$ & $\begin{array}{c}0.0321^{* * *} \\
(0.0031)\end{array}$ & $\begin{array}{c}0.0926^{* * *} \\
(0.012)\end{array}$ \\
\hline E. Nonlinear Counterfactual & $\begin{array}{c}0.0407^{* * *} \\
(0.016)\end{array}$ & $\begin{array}{c}0.0356^{* * *} \\
(0.0053)\end{array}$ & $\begin{array}{c}0.0545^{*} \\
(0.030)\end{array}$ \\
\hline F. Nonlinear \& Incl. Younger & $\begin{array}{c}0.0691^{* * *} \\
(0.0083)\end{array}$ & $\begin{array}{c}0.0327^{* * *} \\
(0.0035)\end{array}$ & $\begin{array}{c}0.0943^{\text {*** }} \\
(0.016)\end{array}$ \\
\hline G. Adding Controls & $\begin{array}{c}0.0747^{* * *} \\
(0.0069)\end{array}$ & $\begin{array}{c}0.0339^{* * *} \\
(0.0033)\end{array}$ & $\begin{array}{c}0.0924^{* * * *} \\
(0.011)\end{array}$ \\
\hline H. Dummy 1999 Reform & $\begin{array}{c}0.0746^{* * *} \\
(0.0065)\end{array}$ & $\begin{array}{c}0.0344^{* * *} \\
(0.0028)\end{array}$ & $\begin{array}{c}0.0978^{* * *} \\
(0.012)\end{array}$ \\
\hline I. Period 2008-2013 & $\begin{array}{c}0.0760^{* * *} \\
(0.012)\end{array}$ & $\begin{array}{c}0.0463^{* * *} \\
(0.0073)\end{array}$ & $\begin{array}{c}0.107^{* * *} \\
(0.024)\end{array}$ \\
\hline J. 2008-2013 \& VERP Eligible & $\begin{array}{c}0.0705^{* * *} \\
(0.011)\end{array}$ & $\begin{array}{c}0.0438^{* * *} \\
(0.0067)\end{array}$ & $\begin{array}{c}0.107^{* * *} \\
(0.025)\end{array}$ \\
\hline K. Retirement Flow Variable & $\begin{array}{c}0.0573^{* * *} \\
(0.0055)\end{array}$ & - & - \\
\hline
\end{tabular}

Notes: This table reports the scaled effect estimates from replicating our main analysis over different specifications of the estimation models (equations 1 and 3) or different sample definitions. Row A reproduces results from our baseline specification, which correspond to those reported in Table 2. Row B replicates the analysis over a sample extended to include reference individuals of ages 55 and 56. Row $\mathrm{C}$ excludes reference individuals aged 59. Row $\mathrm{D}$ keeps reference individuals who turn 60 in December. Row E allows for a nonlinear counterfactual by adding a second order polynomial. Row F implements the two changes applied in B and E. Row G controls for predetermined region and education of reference individuals and spouses. Row $\mathrm{H}$ adds a dummy for individuals born after 1939, who are affected by the 1999 reform. Row I estimates the effect over the period 2008-2013. Row J estimates the effect over the same period as $\mathrm{H}$ and restricts the sample to reference individuals who have contributed to VERP at least once between ages 50 and 59. Row $\mathrm{K}$ reports the estimate for retirement defined as a flow variable, allowing individuals to retire multiple times. Bootstrapped standard errors in parentheses. ${ }^{* *} p<0.01,{ }^{* *} p<0.05$, ${ }^{*} p<0.1$ 
Table 6: The Effect of Increasing Pension Eligibility Age

\begin{tabular}{lccc}
\hline & Retirement & Claiming & Earnings \\
\hline \hline Reference Indiv. & $-0.191^{* * *}$ & $-0.264^{* * *}$ & $8,140^{* * *}$ \\
& $(0.0074)$ & $(0.0065)$ & $(479)$ \\
Spouse & $-0.0172^{* *}$ & $-0.0110^{*}$ & 690 \\
& $(0.0073)$ & $(0.0064)$ & $(532)$ \\
Scaled Effect & $0.0902^{* *}$ & $0.0418^{*}$ & 0.0847 \\
& $(0.038)$ & $(0.024)$ & $(0.065)$ \\
\hline \hline F-test instr. & 662.3 & 1643.6 & 288.8 \\
N. of clusters & 10,321 & 10,321 & 10,321 \\
Observations & 73,395 & 73,395 & 73,395 \\
\hline
\end{tabular}

Notes: This table reports the effect of the 2011 reform, which increased the pension eligibility age. Each column reports results for a different outcome. The first row reports the effect on the individuals affected by the reform (the first stage) and the second row reports the spillover effect to their spouses (the reduced-form effect), which are estimated using equation (5). The third row reports the scaled effect (the LATE) resulting from the 2SLS model estimated in equation (6). Robust standard errors in parentheses, clustered at the couple level. ${ }^{* * *} p<0.01,{ }^{* *} p<0.05$, ${ }^{*} p<0.1$ 
Table 7: Robustness to Alternative Specifications for the Effect of Increasing Pension Eligibility Age

\begin{tabular}{lccc}
\hline & Retirement & Claiming & Earnings \\
\hline \hline A. Baseline & $0.0902^{* *}$ & $0.0418^{*}$ & 0.0847 \\
& $(0.038)$ & $(0.024)$ & $(0.065)$ \\
B. Reweight Spouses Birth & $0.0966^{* *}$ & 0.0324 & 0.0638 \\
& $(0.040)$ & $(0.026)$ & $(0.068)$ \\
C. Donut Affected Spouses & $0.0954^{* *}$ & 0.0380 & 0.0895 \\
& $(0.039)$ & $(0.025)$ & $(0.067)$ \\
D. Without Anticipation & $0.0858^{* * *}$ & $0.0432^{* *}$ & 0.0871 \\
& $(0.032)$ & $(0.021)$ & $(0.053)$ \\
E. Smaller Bandwidth & $0.101^{* *}$ & $0.0494^{*}$ & 0.0932 \\
& $(0.042)$ & $(0.027)$ & $(0.073)$ \\
F. Larger Bandwidth & $0.0590^{*}$ & 0.0320 & 0.0847 \\
& $(0.035)$ & $(0.022)$ & $(0.065)$ \\
G. Not Balancing & $0.0932^{* *}$ & $0.0462^{*}$ & 0.0664 \\
& $(0.039)$ & $(0.024)$ & $(0.069)$ \\
H. Adding Controls & $0.0901^{* *}$ & $0.0415^{*}$ & 0.0822 \\
& $(0.038)$ & $(0.024)$ & $(0.065)$ \\
I. No VERP restriction & $0.104^{* * *}$ & 0.0317 & $0.107^{* *}$ \\
& $(0.034)$ & $(0.021)$ & $(0.055)$ \\
\hline \hline
\end{tabular}

Notes: This table reports the scaled effect estimates (2SLS estimates) from replicating our main analysis using different specifications of the estimation model (equation 6) and different sample definitions. Row A reproduces results from our baseline specification, which correspond to those reported in Table 6 . Row B reweighs the observations so that the treated and control group have the same distribution of spouses' birth date. Row $\mathrm{C}$ excludes spouses born in the first half of 1954. Row D does not estimate the anticipation period separately. Row $\mathrm{E}$ reduces the bandwidth by 2 weeks. Row $\mathrm{F}$ extends the bandwidth by 2 weeks. Row $\mathrm{G}$ does not balance the sample. Row $\mathrm{H}$ controls for region and education of reference individuals and their spouses. Row I extends the sample to include individuals who did not contribute to the VERP program between ages 50-59. Robust standard errors in parentheses, clustered at the couple level. ${ }^{* * *} p<0.01,{ }^{* *} p<0.05,{ }^{*} p<0.1$ 


\section{Appendix A Age Discontinuity Design}

Figure A.1: Alternative Graphical Evidence of the Effect of Pension Eligibility Age on Spouses

(a) Spouse Retirement

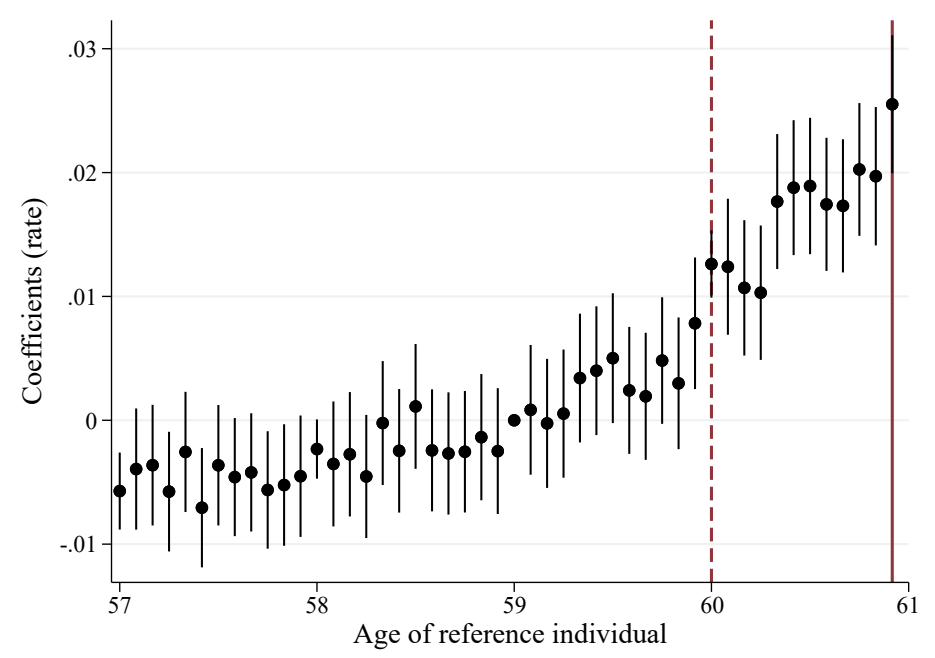

(b) Spouse Claiming

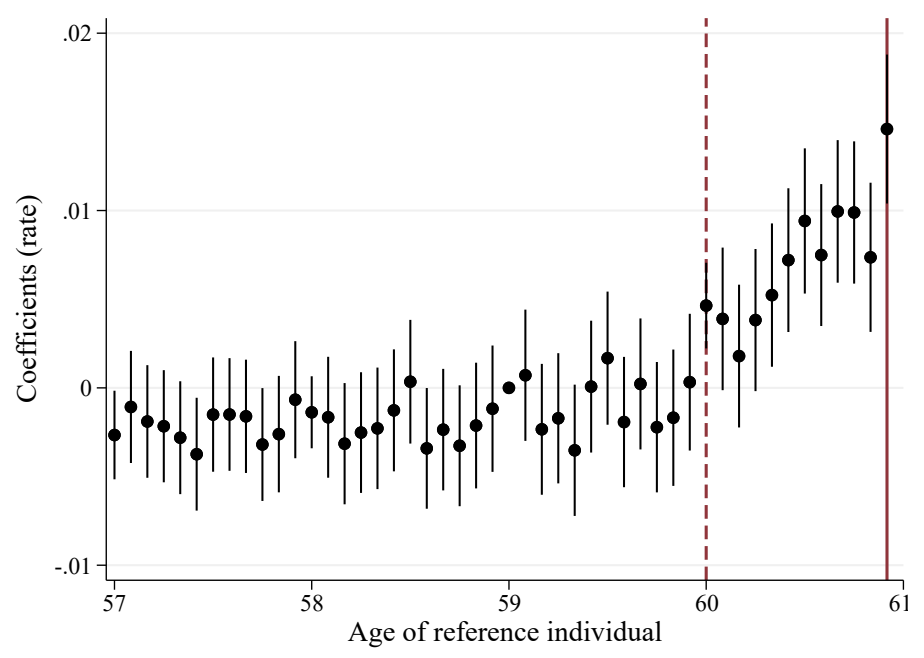

(c) Spouse Earnings

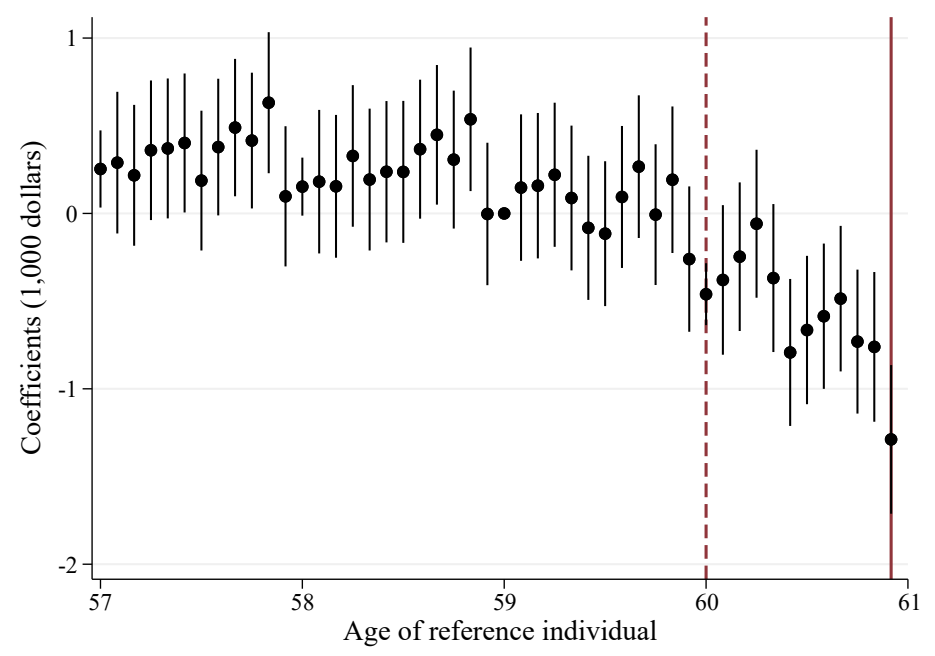

Notes: These figures show an alternative approach to obtain nonparametric evidence on spouses behavior around the pension eligibility age of their partner. They plot the $\delta_{a}^{r}$ coefficients from estimating the regression $y_{i t}^{s}=\alpha+\sum_{a=57}^{62} \delta_{a}^{r} \cdot D_{a}^{r}+\sum_{a=49}^{69} \delta_{a}^{s} \cdot D_{a}^{s}+\sum_{a=49}^{69} \gamma_{a} \cdot D_{a}^{s} \cdot D_{g}+\sum_{c=1991}^{2013} \kappa_{c} \cdot D_{c}+\epsilon_{s t}$, where $y_{i t}^{s}$ are the different outcomes plotted in each figure, $D_{a}^{r}$ are age dummies for the reference individual, $D_{a}^{s}$ are age dummies for the spouse, $D_{g}$ is a gender dummy for the spouse, and $D_{c}$ are calendar year dummies. 
Figure A.2: Placebo Test Assigning Fake Spouses of Similar Age for the Effect of Reaching Pension Eligibility Age

(a) Spouse Retirement

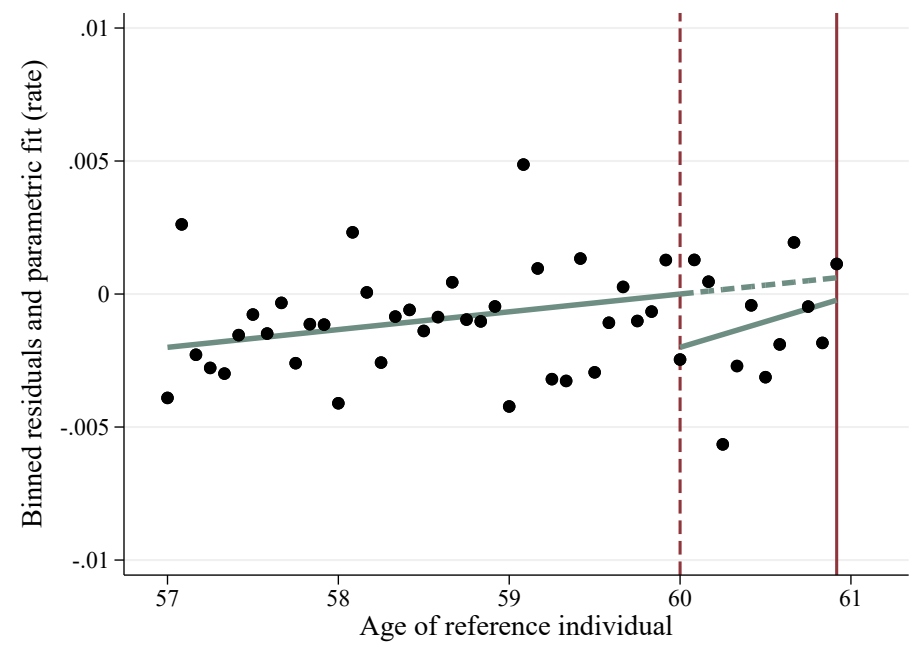

(b) Spouse Claiming

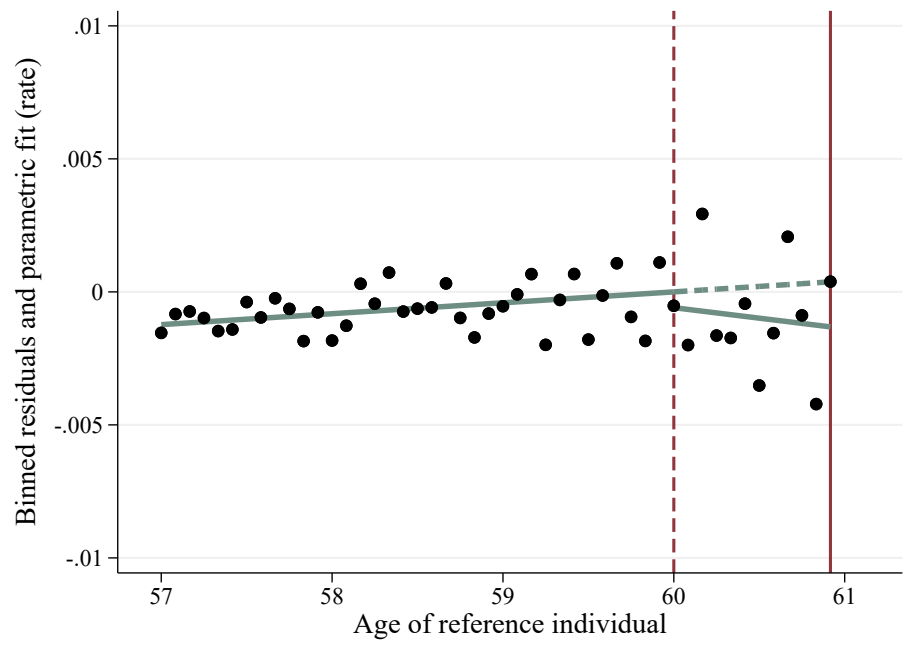

(c) Spouse Earnings

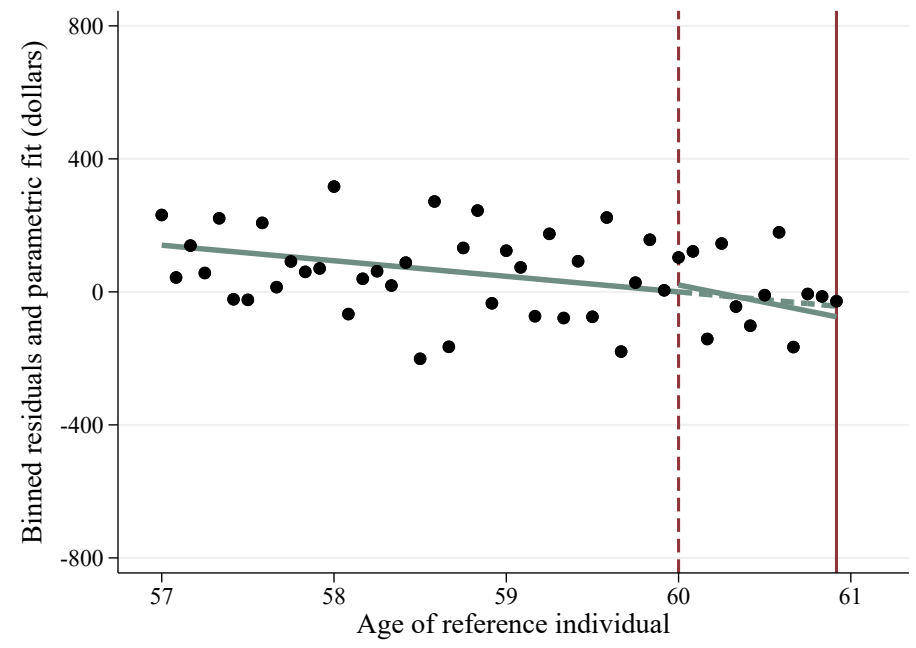

Notes: These figures plot results from replicating the analysis over a placebo sample where the reference individuals are the same as in the main analysis, but they are matched to fake spouses of similar age. The figures show no evidence of joint retirement, as is expected if the research design is valid: fake spouses cannot affect each other's retirement behavior, and the effect coming from the correlation between their ages is controlled for by the empirical design. For more details on the construction of this figure, see the notes of Figure 2. See Appendix Table A.2 for the placebo point estimates. 
Figure A.3: The Effect of Reaching Pension Eligibility Age on Retirement Defined as Flow

(a) Retirement Flow

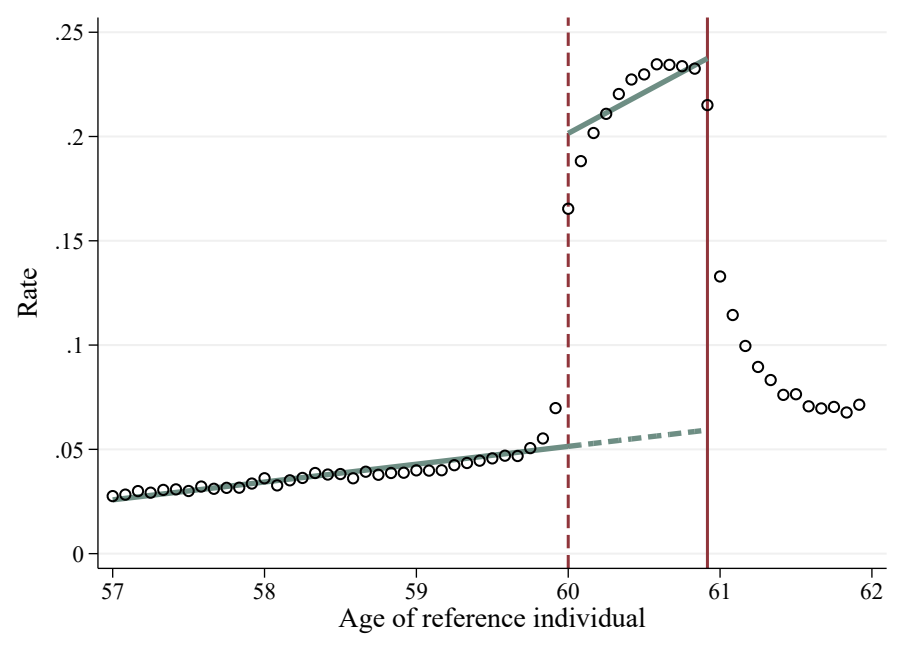

(b) Spouse Retirement Flow

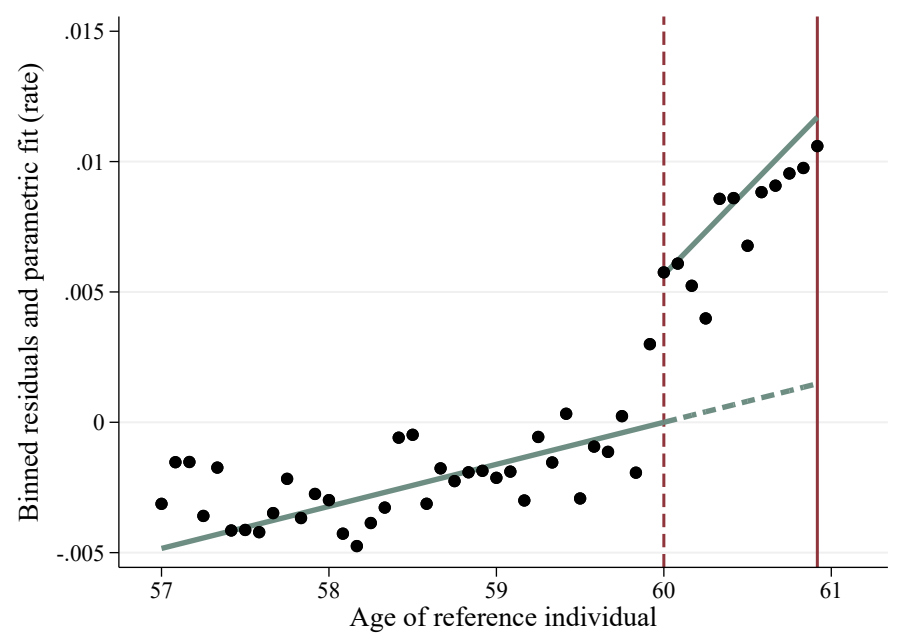

Notes: These figures plot an alternative definition of the retirement outcome, defined as a flow variable that takes the value one in the year in which an individual retires and zero otherwise. For more details on the construction of these figures see notes of Figures 1 and 2. The scaled effect estimate resulting from this outcome is reported in Table 5 . 
Figure A.4: Distribution of Spouses' Age Differences and Earnings Shares

(a) Age Differences, Population

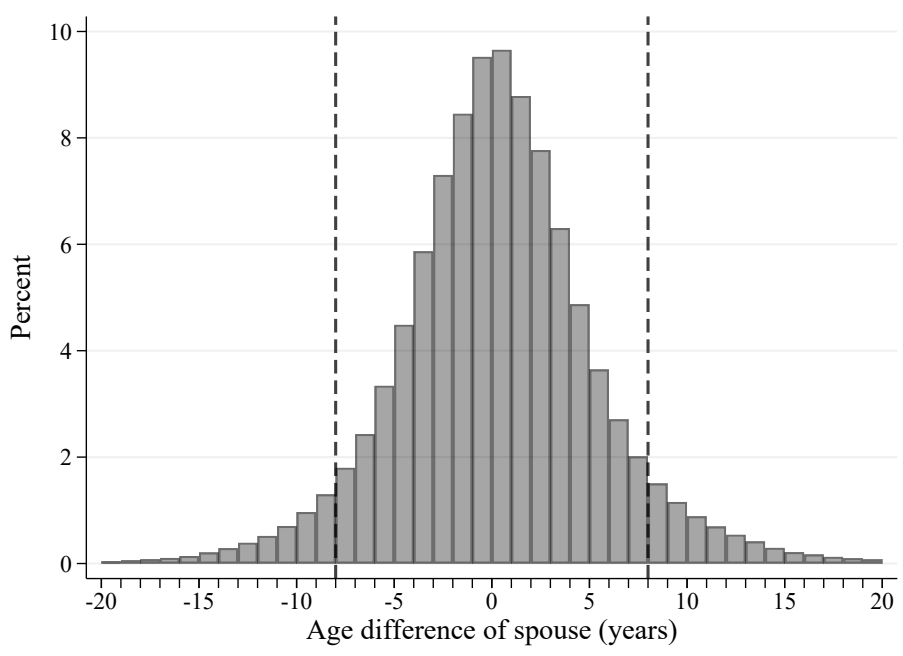

(c) Earnings Shares, Population

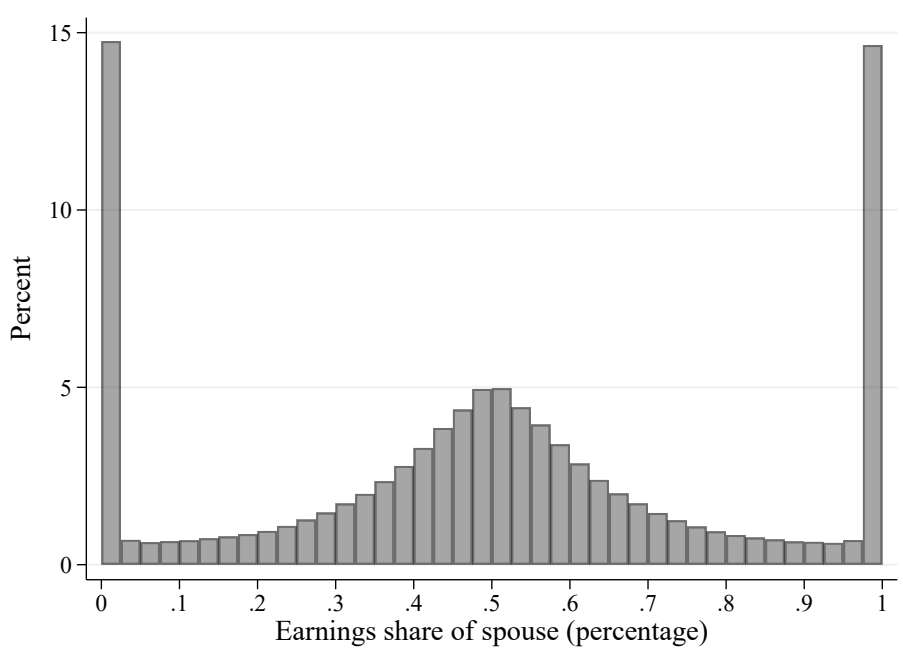

(b) Age Differences, Analysis Sample

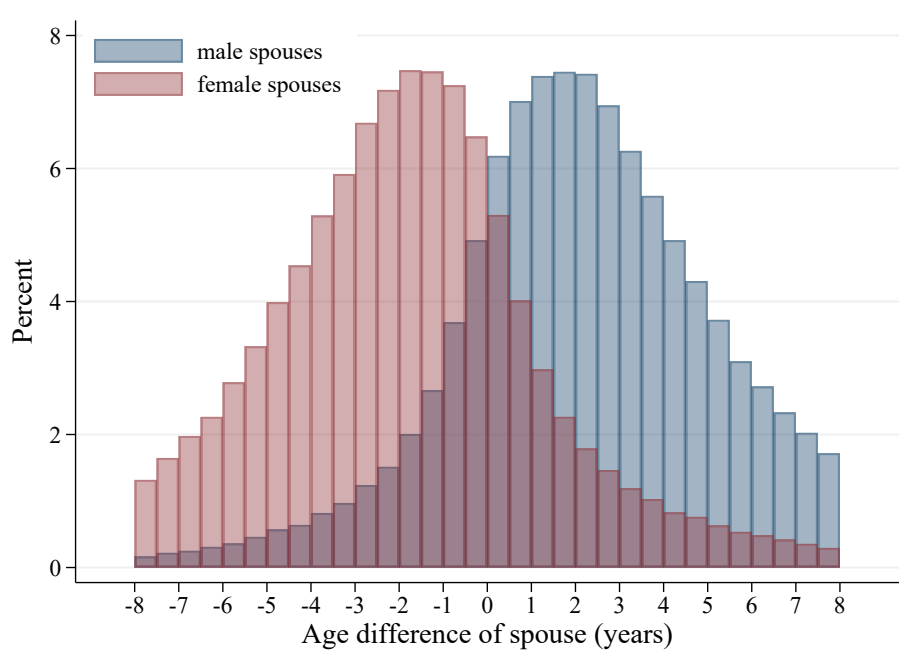

(d) Earnings Shares, Analysis Sample

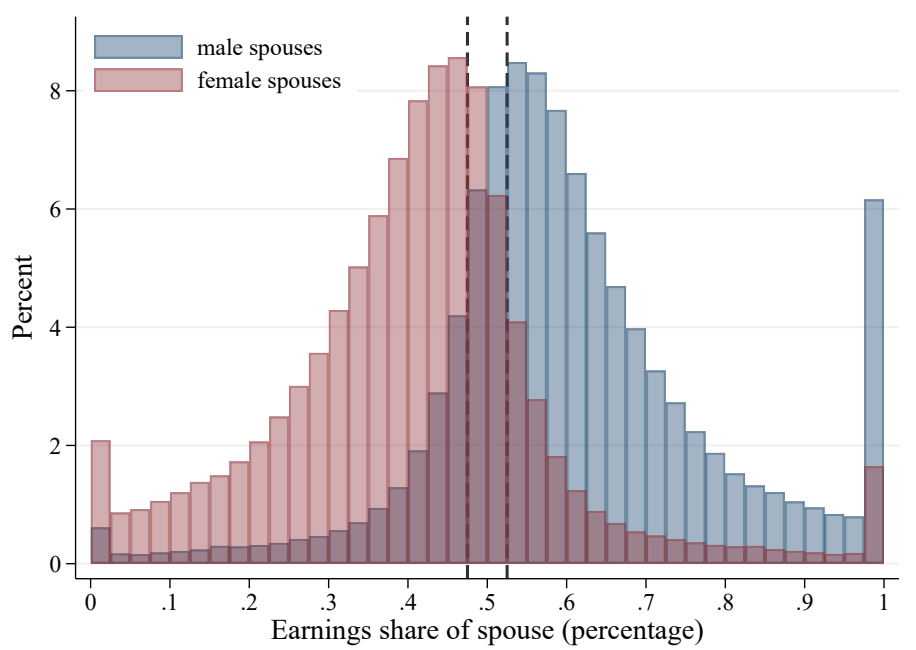

Notes: Panel (a) plots the distribution of age differences within spouses for the population of Danish couples between 1991 and 2013, before applying the sample restrictions described in Section 3.3. The vertical dashed lines mark the tails that are excluded from the sample of analysis, corresponding to couples with more than 8 years difference in age. Panel (b) plots the distribution of age differences for the age-based sample of analysis resulting from imposing the restrictions described in Section 3.3. Panel (c) plots the distribution of earnings shares within the couple, based on average annual labor market earnings of each partner between ages 55 and 57, for the full Danish population between 1991 and 2013. Panel (d) plots earnings shares for the age-based sample of analysis. The vertical dashed lines mark the interval of couples with very similar earnings shares (between 0.475 and 0.525 ) who are excluded in the heterogeneity analysis that defines an indicator variable to identify which member of the couple is the primary earner. 


\section{Figure A.5: The Evolution of Own and Spouse Full-Exposure Effects Over Time}

(a) Retirement

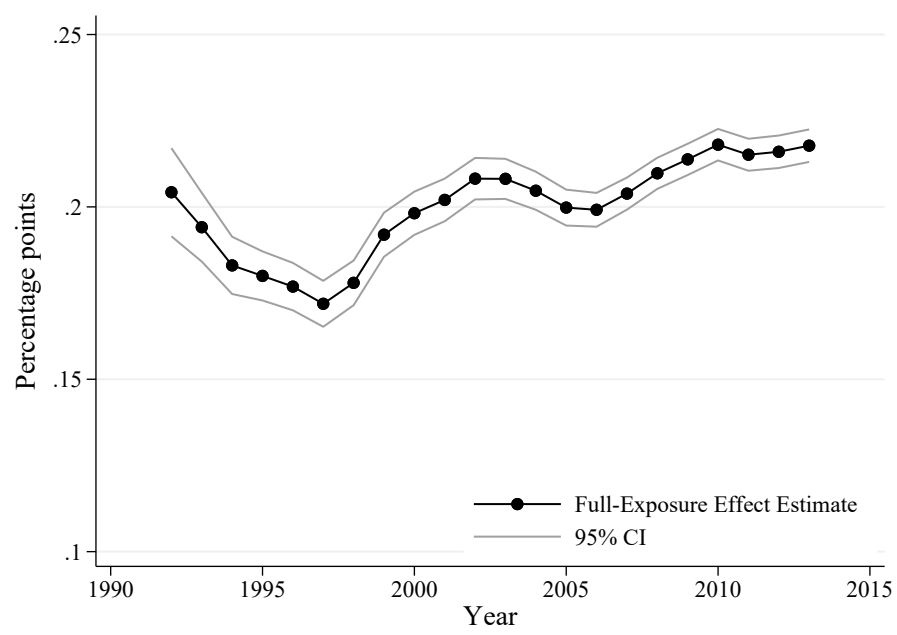

(b) Spouse Retirement

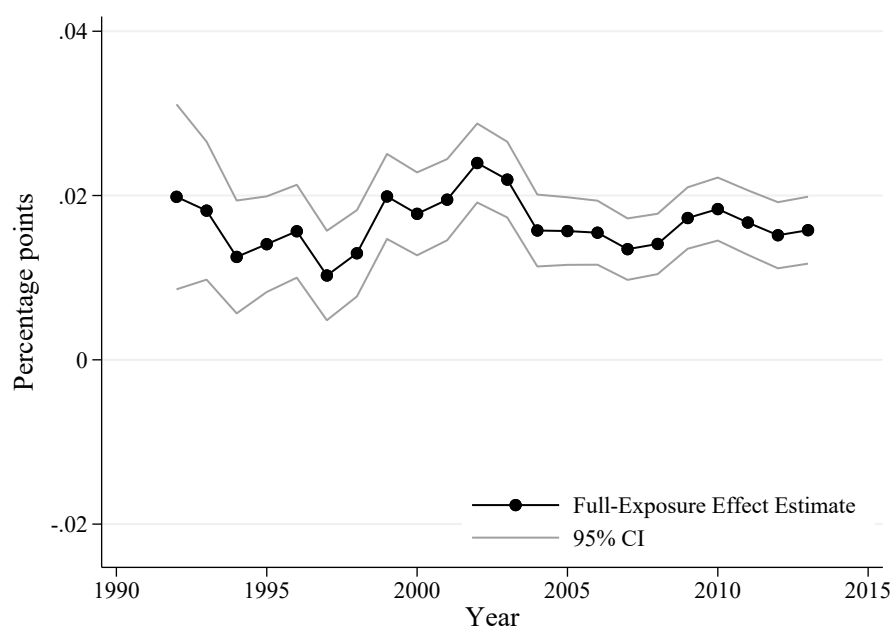

Notes: These figures plot the evolution over time of the full-exposure effect of reaching pension eligibility age for reference individuals and their spouses, for the retirement outcome. These effects are estimated over a 5-year running window using the same methodology as for the full time period, which estimates equations (1) and (3). We report $95 \%$ confidence intervals from robust standard errors clustered at the couple level 
Table A.1: Heterogeneity in the Effect of Reaching Pension Eligibility Age on Retirement Alternative to Reweighting: Interacting Age Differences with Gender

\begin{tabular}{|c|c|c|c|c|}
\hline $\begin{array}{l}\text { Reference Indiv. } \\
\text { Spouse }\end{array}$ & $\begin{array}{l}\text { Young Female } \\
\text { Old Male } \\
(1)\end{array}$ & $\begin{array}{l}\text { Young Male } \\
\text { Old Female } \\
(2)\end{array}$ & $\begin{array}{l}\text { Old Female } \\
\text { Young Male } \\
(3)\end{array}$ & $\begin{array}{l}\text { Old Male } \\
\text { Young Female } \\
(4)\end{array}$ \\
\hline \multicolumn{5}{|l|}{ A. Retirement } \\
\hline Reference Indiv. & $\begin{array}{l}0.2801^{* * *} \\
(0.002)\end{array}$ & $\begin{array}{l}0.1765^{* * *} \\
(0.004)\end{array}$ & $\begin{array}{l}0.2257^{* * *} \\
(0.004)\end{array}$ & $\begin{array}{l}0.1409^{* * *} \\
(0.002)\end{array}$ \\
\hline Spouse & $\begin{array}{l}0.024^{* * *} \\
(0.002)\end{array}$ & $\begin{array}{l}0.030^{* * *} \\
(0.003)\end{array}$ & $\begin{array}{l}0.002 \\
(0.002)\end{array}$ & $\begin{array}{l}0.005^{* * *} \\
(0.001)\end{array}$ \\
\hline Scaled Effect & $\begin{array}{l}0.0872^{* * *} \\
(0.0095)\end{array}$ & $\begin{array}{l}0.167^{* * *} \\
(0.030)\end{array}$ & $\begin{array}{l}0.00954 \\
(0.015)\end{array}$ & $\begin{array}{l}0.0359^{* * *} \\
(0.013)\end{array}$ \\
\hline \multicolumn{5}{|l|}{ B. Claiming } \\
\hline Reference Indiv. & $\begin{array}{l}0.4758^{* * *} \\
(0.002)\end{array}$ & $\begin{array}{l}0.2793^{* * *} \\
(0.004)\end{array}$ & $\begin{array}{l}0.3975^{* * *} \\
(0.004)\end{array}$ & $\begin{array}{l}0.2482^{* * *} \\
(0.002)\end{array}$ \\
\hline Spouse & $\begin{array}{l}0.020^{* * *} \\
(0.002)\end{array}$ & $\begin{array}{l}0.025^{* * *} \\
(0.004)\end{array}$ & $\begin{array}{l}0.000 \\
(0.001)\end{array}$ & $\begin{array}{l}0.000 \\
(0.000)\end{array}$ \\
\hline Scaled Effect & $\begin{array}{l}0.0428^{* * *} \\
(0.0061)\end{array}$ & $\begin{array}{l}0.0878^{* * *} \\
(0.018)\end{array}$ & $\begin{array}{l}0.00413^{*} \\
(0.0025)\end{array}$ & $\begin{array}{l}0.00331^{* * *} \\
(0.0013)\end{array}$ \\
\hline \multicolumn{5}{|l|}{ C. Earnings } \\
\hline Reference Indiv. & $\begin{array}{l}-9,579^{* * *} \\
(93.052)\end{array}$ & $\begin{array}{l}-9,740^{* * *} \\
(248.045)\end{array}$ & $\begin{array}{l}-7,571^{* * *} \\
(166.764)\end{array}$ & $\begin{array}{l}-8,076^{* * *} \\
(114.302)\end{array}$ \\
\hline Spouse & $\begin{array}{l}-1,881^{* * *} \\
(131.71)\end{array}$ & $\begin{array}{l}-1,200^{* * *} \\
(191.19)\end{array}$ & $\begin{array}{l}-284 \\
(226.94)\end{array}$ & $\begin{array}{l}-583^{* * *} \\
(75.48)\end{array}$ \\
\hline Scaled Effect & $\begin{array}{l}0.197^{* * *} \\
(0.023)\end{array}$ & $\begin{array}{l}0.127^{* * *} \\
(0.032)\end{array}$ & $\begin{array}{l}0.0450 \\
(0.052)\end{array}$ & $\begin{array}{l}0.0725^{* * *} \\
(0.016)\end{array}$ \\
\hline N. of clusters & 228,199 & 69,596 & 74,390 & 260,576 \\
\hline Observations & 797,667 & 240,429 & 256,692 & 911,256 \\
\hline
\end{tabular}

Notes: This table reports the effect of the reference individuals reaching pension eligibility age on their own retirement and on their spouses' retirement, distinguishing heterogeneous responses by gender and age composition of the couple. Each column contains results for a different subsample. Each panel reports results for a different outcome variable. Within each panel, the first row reports the full exposure effect of pension eligibility on own retirement as estimated in equation (1). The second row reports the full exposure effect on the spouses of their partners being eligible for retirement pension estimated in equation (3). The third row reports the scaled effect resulting from diving the spouse effect by the own effect. Robust standard errors in parentheses, clustered at the couple level. Bootstrapped standard errors for scaled effects. ${ }^{* * *} p<0.01,{ }^{* *} p<0.05,{ }^{*} p<0.1$ 
Table A.2: Placebo Test with Fake Spouses

for the Effect of Reaching Pension Eligibility Age

\begin{tabular}{lccc}
\hline & Retirement & Claiming & Earnings \\
\hline \hline Reference Individual & $0.2034^{* * *}$ & $0.3496^{* * *}$ & $-8,642^{* * *}$ \\
& $(0.001)$ & $(0.001)$ & $(69.431)$ \\
Spouse & -0.001 & -0.002 & -32 \\
& $(0.001)$ & $(0.001)$ & $(78.79)$ \\
Scaled Effect & -0.00415 & -0.00484 & 0.00370 \\
& $(0.0079)$ & $(0.0035)$ & $(0.017)$ \\
\hline \hline N. of clusters & 367,585 & 367,585 & 367,585 \\
Observations & $2,206,044$ & $2,206,044$ & $2,206,044$ \\
\hline
\end{tabular}

Notes: This table reports the results of replicating the analysis over a placebo sample where the reference individuals are the same as in the main analysis, but they are matched to fake spouses of similar age. The placebo test finds no evidence of joint retirement, as should be expected if the empirical strategy is valid. Fake spouses cannot affect each other's retirement behavior, and the effect coming from the correlation between their ages is controlled for by the empirical design. See the notes of Table 2 for a detailed explanation of the content of the table. Robust standard errors in parentheses, clustered at the couple level. Bootstrapped standard errors for scaled effects. ${ }^{* * *} p<0.01,{ }^{* *} p<0.05,{ }^{*} p<0.1$ 


\section{Appendix B Reform Discontinuity Design}

Figure B.1: Graphical Depiction of the 2011 Reform

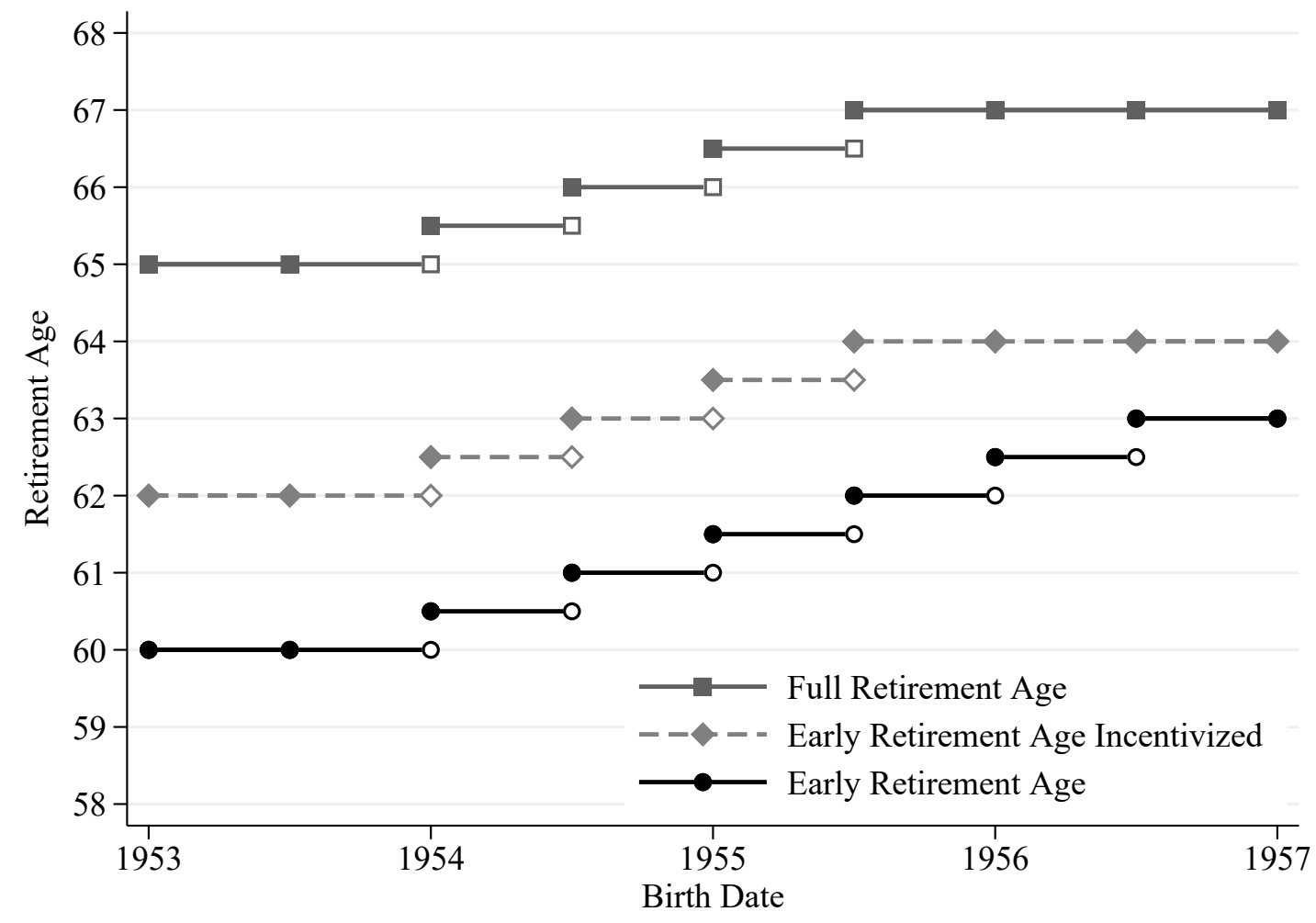

Notes: This figure depicts the 2011 reform that increased retirement ages in 6-month steps contingent on birth date. Cohorts born before January 1, 1954 were unaffected by the reform. Cohorts born between January 1, 1954 and July 1, 1954 experienced an increase of 6 months in their pension eligibility ages. Their early pension eligibility age increased from 60 to $60 \frac{1}{2}$, their incentivized early pension eligibility age increased from 62 to $62 \frac{1}{2}$ and their full retirement pension increased from 65 to $65 \frac{1}{2}$. These individuals constitute our sample of analysis for the reform-based research design that studies the effect of increasing pension eligibility ages. Later cohorts experienced larger increases. 
Figure B.2: Birth Date of Spouses by Treatment Group for the Reform Sample

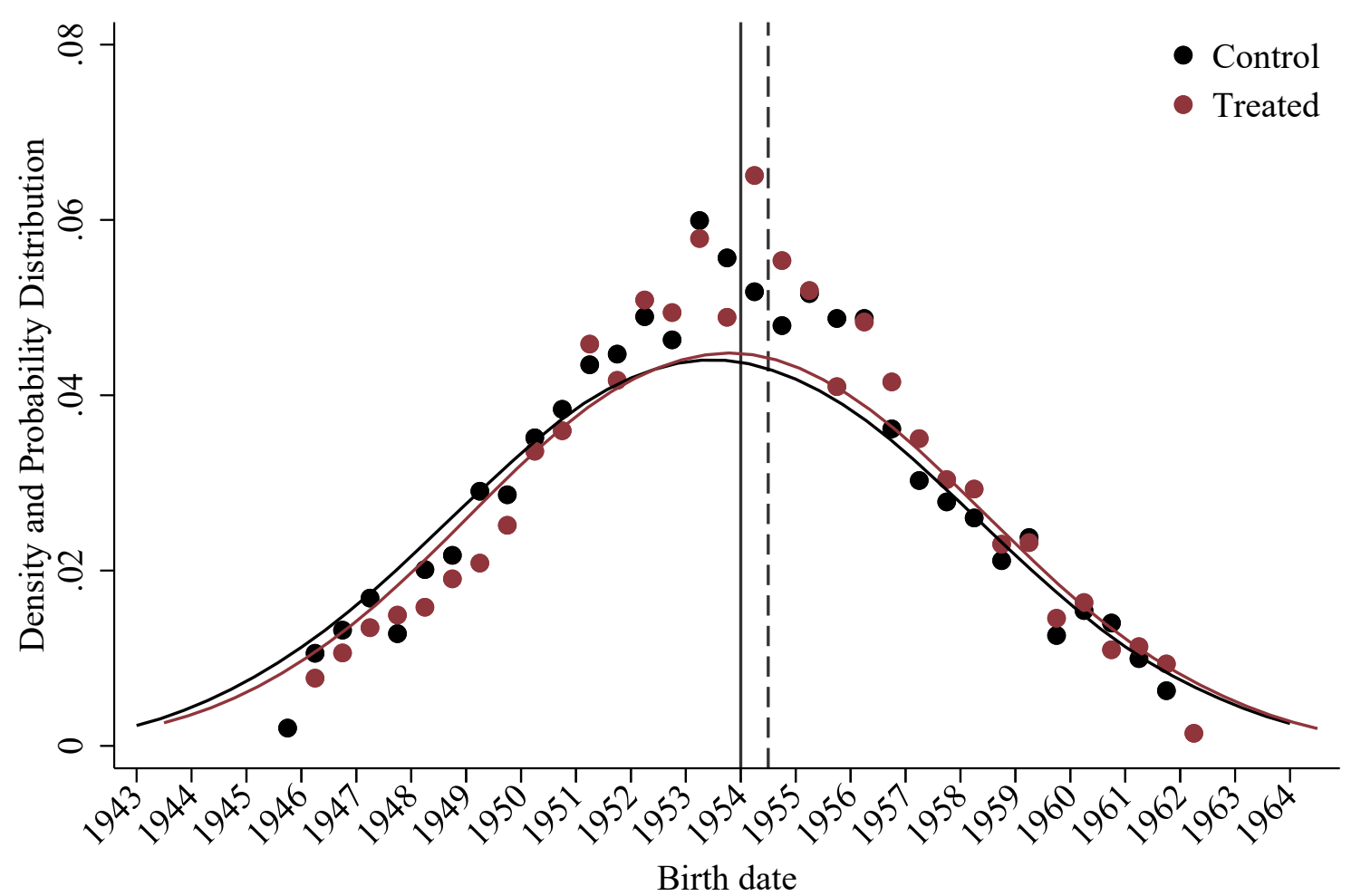

Notes: This graph plots the kernel density function and the probability distribution of the birth date of spouses in the treatment and control groups. Spouses in the treatment group are slightly younger than those in the control group, as a consequence of defining the treatment and control groups based on whether the reference individual was born, respectively, after or before January 1, 1954. Spouses that are born between January 1 and June 30, 1954 (indicated by the solid and dashed vertical lines) are directly impacted by the reform in 2014 . We can see from the probability distribution, which is depicted by the dots, that spouses in the treatment group are 1.3 percentage points more likely to be born within those dates than the spouses from the control group (6.5\% against 5.2\%). Spouses born after June 30, 1954 (dashed vertical line) are impacted by the reform only after 2014. Spouses in the treatment group are 2.2 percentage points more likely to be born after June 30, 1954 (44.3\% against $42.1 \%$ ). 
Table B.1: Heterogeneity in the Effect of Increasing Pension Eligibility Age

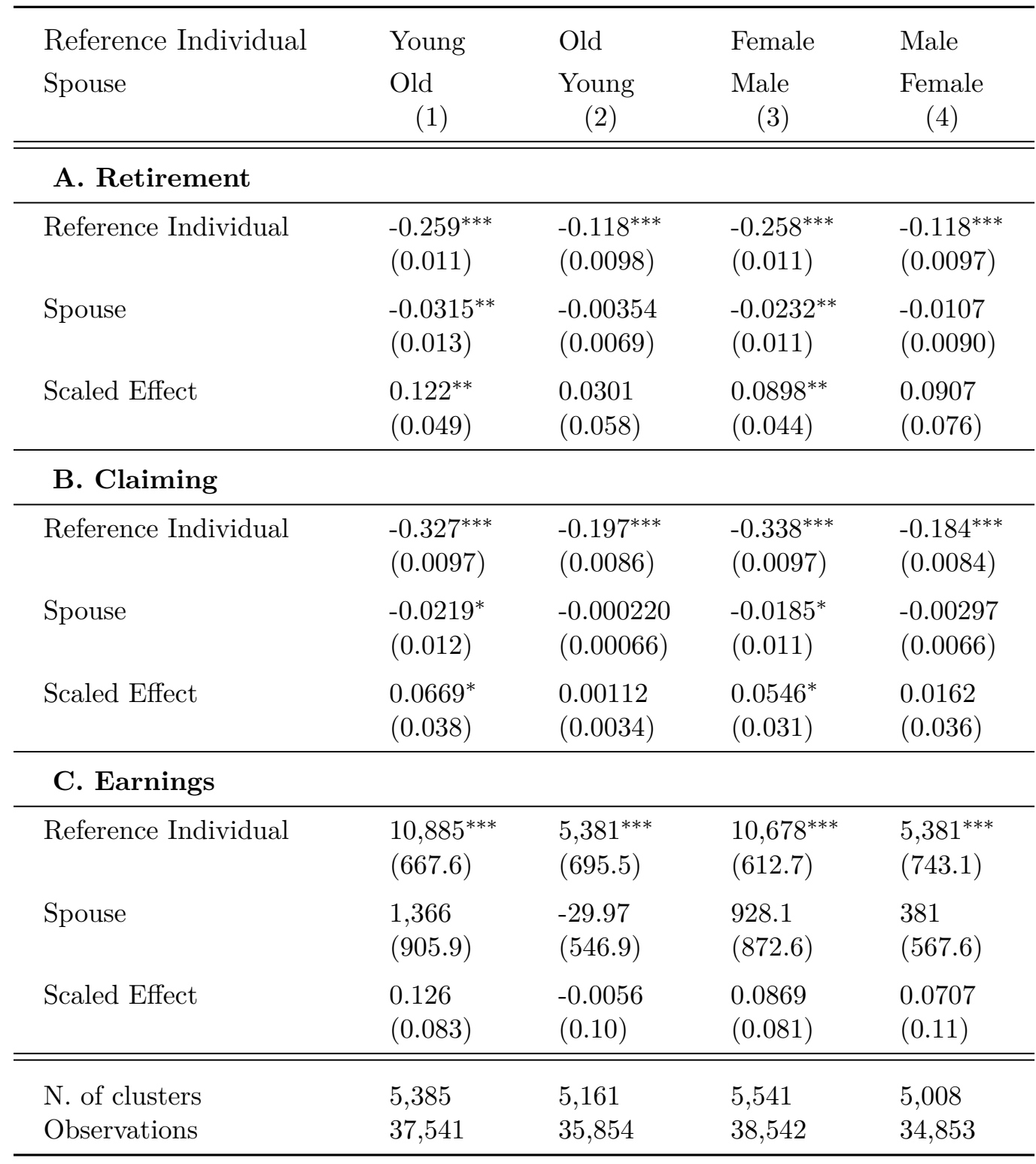

Notes: This table reports the effect of the 2011 reform, which increased the pension eligibility age, distinguishing heterogeneous responses by age composition and gender of the couple. Each column contains results for a different subsample. Each panel reports results for a different outcome variable. Within each panel, the first row reports the effect on the individuals affected by the reform and the second row reports the spillover effect on their spouses, which are both estimated in equation (5). The third row reports the scaled effect (the LATE) resulting from the 2SLS model estimated in equation (6). F-tests for the strength of the instruments are all well above 10. Robust standard errors in parentheses, clustered at the couple level. ${ }^{* * *} p<0.01,{ }^{* *} p<0.05,{ }^{*} p<0.1$ 
Table B.2: The Effect of Increasing Pension Eligibility Age. Replication Over Sample of Spouses At Least 3 Months Older

\begin{tabular}{lccc}
\hline & Retirement & Claiming & Earnings \\
\hline \hline Reference Individual & $-0.258^{* * *}$ & $-0.326^{* * *}$ & $10,718^{* * *}$ \\
& $(0.011)$ & $(0.0099)$ & $(680.8)$ \\
Spouse & $-0.0280^{* *}$ & -0.0179 & 1,480 \\
& $(0.013)$ & $(0.013)$ & $(938.1)$ \\
Scaled Effect & $0.109^{* *}$ & 0.0550 & 0.138 \\
& $(0.051)$ & $(0.039)$ & $(0.087)$ \\
\hline \hline F-test instr. & 523.4 & 1078.6 & 247.8 \\
N of clusters & 5,096 & 5,096 & 5,096 \\
Observations & 35,511 & 35,511 & 35,511 \\
\hline
\end{tabular}

Notes: This table replicates the analysis for a subsample where spouses are at least 3 months older than their partners. This ensures that all spouses are born before January 1, 1954, and therefore are totally unaffected by the 2011 reform. This rules out the possibility that the spillover effect to spouses is driven by spouses in the treated and control groups being diferentially impacted by the reform. See Table 6 for notes on the construction of this table. 